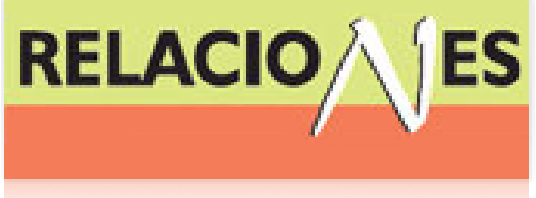

Relaciones. Estudios de historia y sociedad ISSN: 0185-3929

relacion@colmich.edu.mx

El Colegio de Michoacán, A.C

México

Zavala, Agustín Jacinto

LA IDEA DE "CIENCIA JAPONESA" Y LA FILOSOFÍA TARDÍA DE NISHIDA KITARO

Relaciones. Estudios de historia y sociedad, vol. XXXI, núm. 123, 2010, pp. 135-181

El Colegio de Michoacán, A.C

Zamora, México

Disponible en: http://www.redalyc.org/articulo.oa?id=13715893006

- Cómo citar el artículo

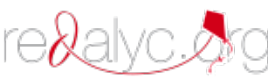

- Número completo

- Más información del artículo

- Página de la revista en redalyc.org

Sistema de Información Científica

Red de Revistas Científicas de América Latina, el Caribe, España y Portugal Proyecto académico sin fines de lucro, desarrollado bajo la iniciativa de acceso abierto 


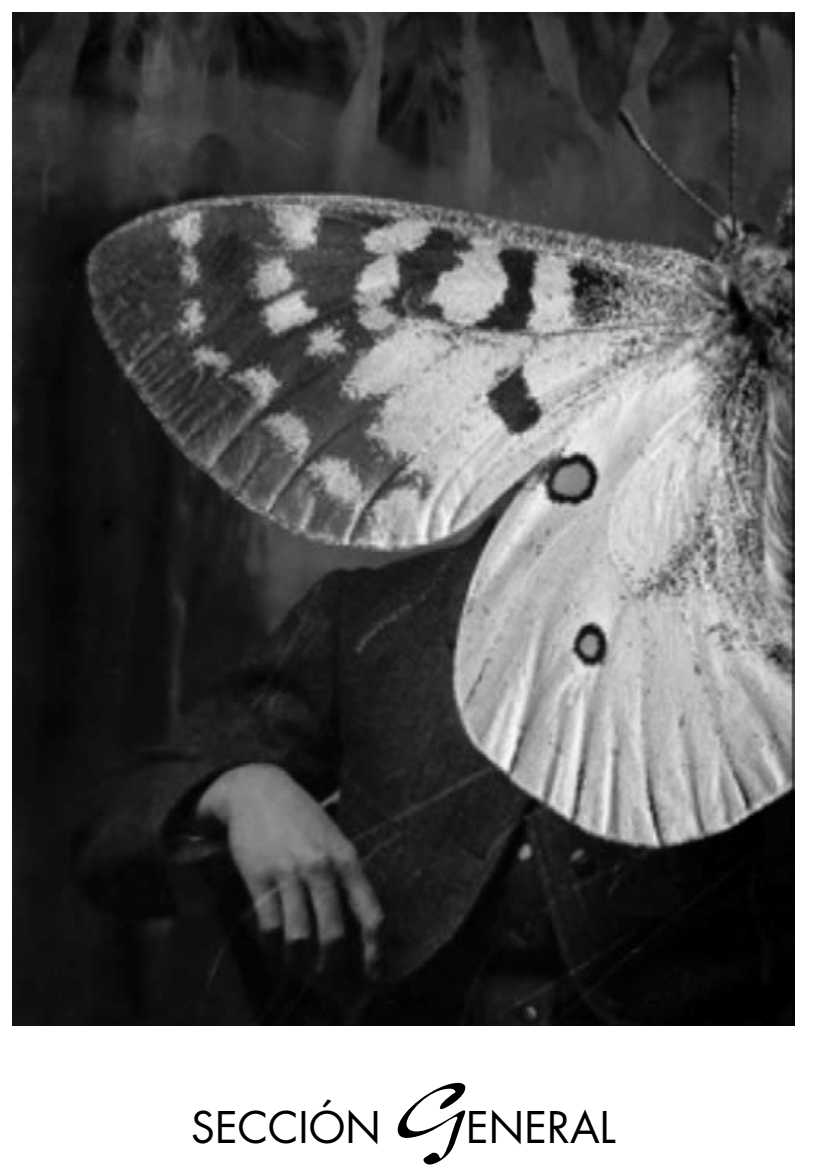




\title{
LA IDEA DE "CIENCIA JAPONESA" Y LA FILOSOFÍA TARDÍA DE NISHIDA KITARO
}

Agustín Jacinto Zavala* El Colegio de Michoacán

\begin{abstract}
Como consecuencia de lo que Nishida caracteriza como despertar de la autoconsciencia del pueblo japonés, es decir, como la percepción de constituir una unidad históricamente diferenciada, en la década de 1930 se exacerba el nacionalismo cultural y se pone énfasis en la peculiaridad de la cultura japonesa. La idea de que en ese tiempo existe ya una "ciencia japonesa" es parte de aquel énfasis. En este texto se busca presentar la manera en que Nishida Kitarô (1870-1945), filósofo japonés, desde el punto de vista de su propio pensamiento filosófico encara la idea de una ciencia japonesa. Para ello se hace una breve exposición de los principales aspectos de la crítica nishidiana a aquella idea que en el primer cuarto del siglo xx todavía resulta exagerada. De esta manera tenemos también un primer acercamiento a la manera en que Nishida piensa la ciencia.
\end{abstract}

(Escuela de Kioto, Nishida Kitarô, ciencia, ciencia japonesa, nacionalismo cultural, axiología, la Nada, intuición activa, autoidentidad de los contradictorios)

INTRODUCCIÓN

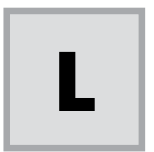

a innovación, la creatividad y la producción del conocimiento utilizando las tecnologías recientes, han sido consideradas en nuestro tiempo como el fundamento de una nueva revolución. Alvin Toffler considera que el foco central de la tercera ola es precisamente el advenimiento de la era del conocimiento, que trae consigo una nueva forma de producir riqueza. Sin embargo, encuentra que uno de los principales obstáculos para su instauración es el desfase en el desarrollo de los diversos elementos socio-

*jacintoz@colmich.edu.mx 
culturales y político-económicos, mismo que se da en mayor o menor medida en cada país. Dependiendo del desfase de que se trate, serán los obstáculos que se presenten a la producción de nuevo conocimiento. Este mismo tema ha sido objeto de muchos otros estudios. ${ }^{1}$ En el caso de Japón de la primera mitad del siglo xx el problema fue la limitación de la investigación académica.

En la década de 1930, Nishida ve con mucha preocupación las fuertes tendencias de derecha y el militarismo gubernamental, que llevaron a la severa limitación de la investigación académica. Contra esto, Nishida reacciona de varias maneras: se afilia al movimiento por la libertad académica, trata de ejercer su influencia en las altas esferas gubernamentales para que no se coarte esa libertad, trata de convencer a sus discípulos de que sigan investigando, etcétera. Pero algo que fue notable, y que, incluso puso en peligro su vida, fue su actividad como conferencista y autor preocupado por la necesidad de producción de nuevo conocimiento.

En el otoño de 1937 dicta una conferencia en el auditorio del parque Hibiya, en Tokio, sobre "El método filosófico" y en 1938 dicta tres conferencias bajo el título general de "Problemas de la cultura japonesa". Este fue apenas el inicio de su abierta oposición en contra de la falta de libertad académica que retrasaba la investigación científica.

Pero en la década de los treinta se empezó a hablar, cada vez con mayor insistencia, acerca de la "ciencia japonesa". Esto implicaba tres cosas: a) que había ya una ciencia de nivel mundial en la gran potencia que era Japón; b) que esa ciencia era propia del Japón, exhibiendo características propias de Japón; y c) que la etnia japonesa había llegado a desarrollar una ciencia en la cual podía verse la quintaesencia del "Espíritu japonés". En otras palabras, esa ciencia japonesa debía ser peculiar, porque la cultura que la había producido tenía un desarrollo diferente al de las naciones occidentales y tenía sus propios criterios y valores.

Nishida reacciona contra la superficialidad que implica revestir la ciencia con conceptos tomados de los pensadores japoneses antiguos

\footnotetext{
${ }^{1}$ Alvin Toffler-Heidi Toffler, La revolución de la riqueza, México, Debate, 2006. Id. La creación de una nueva civilización: la politica de la tercera ola, Barcelona, Plaza y Janés, 1996. Ikujiro Nonaka-Hirotaka Takeuchi, The Knowledge Creating Company, Nueva York, Oxford University Press, 1995. Lester C. Thurow, Construir riqueza, Buenos Aires, Javier Vergara Ed., 2000.
} 
mientras se mantiene, conservando los vocablos originales en lenguas extranjeras, el significado occidental actual. Nishida dice que la transformación de la ciencia occidental en ciencia japonesa no depende solamente de que se exprese con términos tradicionales japoneses. Más bien, lo básico está en expresar una nueva manera de concebir los fenómenos o de presentar sus relaciones y no en simplemente encontrar un vocablo japonés para sugerir una trasposición de significado. Por esto, vamos ahora a examinar lo que Nishida consideró como "ciencia japonesa".

Este tema se presta para ver un aspecto de lo que Nishida considera como ciencia y su caracterización como producto específico en la cultura japonesa. Por eso, para ver la manera en que Nishida hace frente al problema de la ciencia japonesa, vamos a examinar brevemente ocho puntos que dividiré en tres partes: I) El problema: la ciencia japonesa. II) Lo que se va a conocer y manera de conocerlo. III) La manera en que estudia la ciencia.

El problema: la "CienCia JAPONeSA"

Como ya se dijo, este fue un tema sobre el que se puso énfasis en tiempos del militarismo japonés, cuando se exaltó el nacionalismo cultural y se trató de construir la Gran Esfera de Coprosperidad de Asia. Vamos a ver la manera en que Nishida lo aborda, presentando lo que Nishida considera "lo japonés", y luego los requerimientos básicos para una ciencia que pueda decirse "japonesa".

"Lo japonés" en Nishida

En octubre de 1917, Nishida publicó el artículo "Acerca de lo japonés" en la revista Shisô. ${ }^{2}$ Allí se refiere a la tendencia en el mundo académico de Japón a afirmar que cada país tiene una cultura peculiar y así como los japoneses no pueden comprender verdaderamente la cultura occi-

\footnotetext{
${ }^{2}$ Véase Nishida Kitarô Zensh $\hat{u}$ (Obras completas de Nishida Kitarô), Tokio, Iwanami shoten, vol. XIII, 1966-1968, 116-120. En adelante sólo se indicará el número de volumen en numeros romanos y el número de página en arábigos.
} 
dental, tampoco los extranjeros pueden entender la cultura japonesa. Nishida dice: "esta tendencia del pensamiento me alegra como autopercepción de nuestro pueblo y, al mismo tiempo, debo ser suficientemente crítico de ella". ${ }^{3}$ Analiza primero lo que es una ley universal. Las hay de dos tipos: las primeras son descriptivas, como es el caso de las leyes de la causalidad; y las segundas son normativas, como es el caso de las leyes de los juicios axiológicos. ${ }^{4}$ Generalmente se entiende que las leyes de las ciencias naturales son del primer tipo y las de las ciencias práxicas son del segundo tipo.

En los fenómenos "espirituales" o intelectuales de una cultura hay una parte que es creativa e individual, aunque como existencia natural todos estamos sujetos a las leyes naturales. Pero "las leyes de la naturaleza son leyes de existencia", ${ }^{5}$ y la existencia de la cultura sigue las leyes de la naturaleza como actividad integradora que es creativa: "las leyes de la naturaleza no pasan de ser un aspecto abstracto de la realidad creativa". En una cultura hay cosas que pertenecen al gusto, a la idiosincrasia personal y en ese caso, ciertamente, en cuestión de gustos no hay discusión. No pasan de ser cuestiones particulares o individuales. Hay otras que van acompañadas de la certeza de su validez universal y del requerimiento de que así sean consideradas por otros. Este es el caso de los valores morales o de los valores artísticos. Pero quienes ya en 1917 predicaban "lo japonés" menospreciaban este segundo aspecto y daban énfasis al primero. El paso entre lo que es el gusto personal y lo que tiene validez universal está en entrar al dominio público y dejar de pertenecer a un grupo o pueblo. Se hace universal porque a) ha perdido su carácter de pertenencia restringida a un individuo que es japonés; $b$ ) ha entrado al dominio público; c) al entrar al dominio público deja de ser de los japoneses; $\mathrm{y} d$ ) va acompañado del requerimiento de que se reconozca su validez universal. ${ }^{6}$

Aunque Nishida reconoce que un valor artístico tiene un elemento particularista, sin embargo, afirma que aquello que de ninguna manera

\footnotetext{
${ }^{3}$ XIII: 116.

${ }^{4} \mathrm{Ibid}$.

${ }^{5}$ XIII: 117.

${ }^{6}$ XIII: 118.
} 
puede ser comprendido por los otros no merece el nombre de bello o de bueno: "allí reside la diferencia entre la idiosincrasia y el gusto artístico". La situación de hecho, sin embargo, es que quizá ni los japoneses hayan comprendido los gustos del exterior ni los extranjeros hayan realmente comprendido el gusto japonés; $y$, además, el desarrollo artístico y moral de cada país en particular se fundamenta en la historia de ese país: cada uno hace su contribución a la cultura desde su propio punto de vista. Pero una cultura particular debe tener valores universales. Esto no significa que todos en todo lugar deban crear lo mismo o tener los mismos gustos: significa que todos deben reconocer esos valores. La igualdad no es unificación sino que hay diferencias. Aun en lo que demanda la comprensión de todos hay diferencias: "no debemos olvidar que en el fondo del corazón de todos hay un significado unitario". ?

Quienes en 1917 propalaban la idea de "lo japonés" confundían estos dos aspectos: confundían "lo igual" con "lo mismo", lo que en todos es igual y el que todos deban tener lo mismo. Es decir, rechazaban lo universal y enfatizaban lo japonés; al hacerlo negaban lo universal y con ello se perdían los valores. Frente a eso la posición de Nishida era la siguiente: "desarrollar más y más la cultura particular, al mismo tiempo, que esa cultura venga a ser elemento indispensable de la cultura mundial". ${ }^{8}$ Este problema, así enunciado, vino a ser posteriormente el meollo de la obra Problemas de la cultura japonesa, que Nishida dictó como conferencias en 1938 y que publicó como libro en $1940 .^{9}$

En el periodo temprano Nishida expresa un panasianismo que no vuelve a expresar de la misma manera, pero que aquí nos interesa no sólo para la ciencia sino para la cultura japonesa en general: "desechando todo dogmatismo gratuito y criticándolo e investigándolo al desnudo, con la conciencia artística que emana desde el fondo de nuestro corazón, quisiera ver con confianza en la cultura de nuestro país que tanto chinos como coreanos lleguen [a tener] Yamato-gokoro [alma de Yamato= espíritu japonés]. De esta manera nace la verdadera cultura japonesa

\footnotetext{
${ }^{7}$ XIII: 119.

${ }^{8}$ XIII: 119-120.

${ }^{9}$ Agustín Jacinto Z. La filosofía social de Nishida Kitarô: 1935-1945, Zamora, El Colegio de Michoacán, 1995. Capítulo I, “La justificación de una cultura diversa”, pp. 41-58.
} 
viviente". Es decir, Nishida busca "en el trasfondo de la cultura de Japón un espíritu profundo y vasto", por eso agrega: "también en el fondo de nuestro corazón que ama a la flor del cerezo, quiero saborear una filosofía de la voluntad creadora como la de Nietzsche cuando dice 'amo al que cae abatido por crear algo superior a sí mismo ${ }^{\prime \prime} .{ }^{10} Y$ es con esa voluntad creadora con la que Nishida quiere "hacer revivir a nuestros ancestros en este cuerpo y en esta sangre" recibiendo la historia como una fuerza. ${ }^{11}$ En el discurso pronunciado en ocasión de la muerte de su hermano Hyôjirô en 1904, Nishida Kitarô había dicho: "en especial, al pensar que el resultado de esta guerra es la expansión en Asia Oriental de la fuerza de nuestro país y que sus restos [=de Hyôjirô] vienen a ser la base de un nuevo Imperio, no puedo contener una gran emoción". ${ }^{12}$ De tal manera que Nishida, partidario de un Estado fuerte, veía la expansión de lo japonés como una contribución a la cultura mundial.

En el escrito de julio de 1935 titulado Acerca de mi "Mundo de la personalidad", Nishida clarifica varias nociones fundamentales. Aquí nos interesa hacer destacar las siguientes:

a) Respecto a la relación entre peculiaridad individual y el todo, escribe: "donde cada quien mantiene sus características peculiares mientras forma un todo, allí está la verdadera cultura".

b) Respecto a las culturas oriental y occidental dice: "pienso que las culturas oriental y occidental difieren fundamentalmente".

c) Pero aclara su postura política: "sólo que pienso que sin caer en un estatismo estrecho y exclusivista, debemos dar origen a una gran cultura mundial desde el fondo de nuestra vida histórica".

d) La misión de la etnia o pueblo japonés la concibe de la siguiente manera: "absorber a la cultura occidental desde el punto de vista de la cultura oriental y contribuir a la cultura mundial debe ser una misión que solamente tiene nuestra etnia [o pueblo]". ${ }^{13}$

\footnotetext{
${ }^{10}$ "Yo amo a quien quiere crear por encima de sí mismo y perece por ello", Friedrich Nietzsche, Asíhabló Zaratustra, Parte I, "El camino del hombre creador", en Obras selectas, Madrid, Edimat libros. s. f. p. 74.

${ }^{11}$ XIII: 120.

${ }^{12}$ XIII: 170

${ }^{13}$ XIII: 135 .
} 
Hacia una "ciencia japonesa" en Nishida

En el prefacio que en 1918 Nishida escribió al libro Investigaciones sobre filosofía de las matemáticas del entonces neokantiano Tanabe Hajime, escribe: "el filósofo ve desde el punto de vista filosófico y trata acerca del carácter del conocimiento científico; no aporta datos al conocimiento científico mismo" ${ }^{14}$ En 1924 escribió el prefacio al libro Materiales para la educación matemática en el que trata de la relación entre filosofía y matemáticas. Dice que desde la antigüedad ha sido estrecha la relación entre ambas: en Platón, Plotino, Nicolás de Cusa, Descartes, Leibniz, Georg Cantor y, recientemente, en Hermann Cohen de la Escuela de Marburgo, que han sido notables filósofos y notables matemáticos. ${ }^{15}$

Nishida resume en cuatro puntos las relaciones entre filosofía y matemáticas:

a) aunque difiere de las matemáticas, la filosofía exige una lógica y deducción exactas, por eso el filósofo necesita una mente matemática;

b) muchos conceptos matemáticos, como infinito, continuidad, etcétera, directamente sirven en filosofía;

c) quizá en las diversas relaciones entre los números se incluyan las formas puras de la realidad, ${ }^{16} \mathrm{y}$ así como los zoólogos buscan un arquetipo o prototipo de animal primitivo, también en las relaciones matemáticas se encuentren las formas puras de la realidad; y sin embargo,

d) ni los resultados de las investigaciones matemáticas pueden utilizarse directamente en la filosofía, ni la verdad matemática es tal cual verdad filosófica. ${ }^{17}$

Ante todo quisiera presentar el aspecto léxico de lo que Nishida denomina ciencia. En su vocabulario hay dos vocablos para designar la ciencia. El más general, que incluye toda forma de conocimiento organi-

\footnotetext{
${ }^{14}$ XIII: 196.

${ }^{15}$ XIIII: 208-209.

${ }^{16}$ XIIII: 210.

${ }^{17}$ XIII: 211.
} 
zado, formalizado y estricto, recibe el nombre de gakumon, es decir, la ciencia en el sentido de lo que es académico. El vocablo más particularizado es kagaku, que traduce Wissenschaftlen] o science(s), e incluye muchas variedades: ciencias naturales, ciencias sociales, ciencias históricas, ciencias matemáticas, ciencias biológicas, ciencias físicas, ciencias empíricas, ciencias del espíritu (Geisteswissenschaften), ciencias políticas, ciencias del Estado (Staatslehre), ciencias religiosas, etcétera. Para Nishida, la ciencia en ambos casos tiene características generales que apuntaremos hacia el final.

En 1924, Nishida critica el concepto de ciencia en general que se basa en el principio de causalidad de las ciencias naturales y busca sustituirla por el principio de causalidad originada en la Idea (del "mundo de las ideas" de Platón). Este tipo de causalidad tiene como su fundamento el desarrollo de la Idea. La Idea que se ve a sí misma es origen del tiempo y, por tanto, en ella se origina también la causalidad. ${ }^{18}$ En 1927 critica la separación entre percepción y pensamiento resultante de olvidar que Kant logró unirlos estrechamente como unidad de forma y contenido, y que según esta manera de pensar la ciencia requiere una reinterpretación de lo dado y de la subjetividad cognoscente. ${ }^{19}$ Nishida considera que esa reinterpretación profundiza más la manera de ver el mundo de los objetos, lo cual debe hacerse sobre la base de su concepto de autopercepción intelectual-que unifica percepción y pensar-y autopercepción de la voluntad, por penetrar más profundamente en la subjetividad. ${ }^{20} \mathrm{Ve}$ en el Tathandlung (hecho-acción) la base primaria, pura e incondicional de todo conocimiento y toda ciencia, a la manera de Fichte. ${ }^{21}$ Pero tomar la experiencia autoperceptiva como base de las ciencias implica pensarlas de diversas formas..$^{22}$ Más tarde, en 1930 dice que cada una de las ciencias particulares se constituye mediante una determinación específica de lo intuitivo, esto es, mediante una determinación del topos o bas$h o{ }^{23}$ En este sentido, es necesario tener consciencia de que la verdadera

\footnotetext{
${ }^{18} \mathrm{IV}: 71$.

${ }^{19} \mathrm{IV}: 307$.

${ }^{20} \mathrm{IV}: 307-308$.

${ }^{21} \mathrm{IV}: 310$.

${ }^{22} \mathrm{~V}: 430$.

${ }^{23}$ VI: 112.
} 
realidad no se limita a la sola realidad como objeto de conocimiento, ${ }_{,}^{24} \mathrm{ni}$ sólo a lo que es activo en tanto que se mueve y actúa en el tiempo, ${ }^{25} \mathrm{ni}$ sólo a lo físico. ${ }^{26}$

Si se pone énfasis sólo en que la ciencia es conocimiento objetivo resulta un concepto unilateral de ciencia, porque "desde el punto de vista del conocimiento objetual no se puede retornar al mundo de la autopercepción" ${ }^{27}$ Aunque se introduzca el concepto de ciencias descriptivas y ciencias comprensivas, en tanto que la comprensión en éstas es puramente abstracta, ambas se quedan en un estudio de lo concreto. ${ }^{28}$ En este sentido, el error de Fichte consiste en que "en lugar de pensar la autodeterminación del sí-mismo que es Nada, pensó el sí-mismo inmediatamente en dirección noemática y al pensar de esa manera cayó en la metafísica".$^{29}$

La filosofía es una ciencia humanística que tiene como centro al ser humano autoperceptivo, y que "se constituye mediante la autodeterminación de lo que no tiene determinante, se constituye mediante un punto de vista sin punto de vista. Además, eso no es que simplemente no tenga ningún punto de vista sino que debe ser el punto de vista de la verdadera autopercepción".$^{30}$ Por eso, puede establecerse una diferencia entre ver "lo determinante a partir de lo determinado, que es el punto de vista de la ciencia" y "ver lo determinado a partir de lo determinante, que es el punto de vista de la filosofía" ${ }^{31}$ En tanto no toma su punto de partida en la autopercepción del si-mismo activo, la fenomenología de Husserl y la fenomenología hermenéutica de Heidegger, "no pasan de ver los 'hechos' autodeterminativos de la comprensión" y aunque Heidegger afirme "que su punto de vista es el del logos, éste no es, como en Hegel, el punto de vista de la autopercepción del logos mismo". ${ }^{32}$

\footnotetext{
${ }^{24}$ VII: 9.

${ }^{25}$ VII: 64,78 .

${ }^{26}$ VII: 76 .

${ }^{27}$ VI: 143.

${ }^{28} \mathrm{VI}: 170$.

${ }^{29} \mathrm{VI}: 171$.

${ }^{30} \mathrm{~V}: 112$.

${ }^{31}$ VI: 173.

${ }^{32}$ VI: 179.
} 
Por una parte, Nishida señala que "mediante la metafísica griega no puede fundamentarse la realidad científica moderna" ${ }^{\prime 33} y$, por otra, que "el mundo histórico no solamente es el mundo de los objetos de nuestra comprensión sino que debe ser aquello que determina a nuestra acción". ${ }^{34}$ Apunta además que "la razón en la ciencia moderna no es idéntica al nous de la filosofía griega", sino que esa razón en la ciencia moderna "debe ser algo que ha llevado a fondo el punto de vista de la negación de la subjetividad". ${ }^{35}$ Además, señala que la naturaleza no debe ser considerada simplemente como el reino de la necesariedad. ${ }^{36}$ Nishida dice que dado que la realidad histórica misma es dialéctica, "las ciencias deben criticarse desde el punto de vista dialéctico", ${ }^{37}$ porque no debe verse el mundo dialéctico con lógica objetual. ${ }^{38}$

Vamos a entender la ciencia, como lo hizo Nishida, siguiendo el operacionalismo del físico Percy Williams Bridgman $(1882-1961)^{39}$ y del psicólogo Stanley Smith Stevens (1906-1973) 40: "la ciencia es el conocimiento sobre el que hay acuerdo entre los miembros de una sociedad. Sólo aquellos constructos basados en operaciones públicas y repetibles son admitidos al cuerpo de la ciencia" ${ }^{41}$ Esta definición tiene la ventaja de restringir un poco el énfasis en la universalidad de la ciencia y en no poner mucho énfasis en la causalidad como el medio de conocimiento específico de la ciencia. Sin embargo, Nishida señala también que "la ciencia es enteramente un punto de vista que refleja al mundo poieticamente, es decir, un punto de vista que expresa simbólicamente al mun-

\footnotetext{
${ }^{33}$ VII: 79.

${ }^{34}$ VII: 179.

${ }^{35}$ VII: 440 .

${ }^{36}$ VIII: 83.

${ }^{37}$ VIII: 4.

${ }^{38} \mathrm{VIIII}: 241$.

${ }^{39}$ Nishida leyó sus obras The Logic of Modern Physics (1927) y The Nature of Physical Theory (1936) en las que, siguiendo ideas parecidas a las de Peirce en "How to make our ideas clear" (1878), Bridgman propone la definición operativa de los conceptos polisémicos o polivalentes.

${ }^{40}$ Stevens aplicó las ideas operacionalistas a la psicología. Nishida propuso un procedimiento operacionalista en las ciencias naturales, quizá debido al empiricismo radical heracliteano que él mismo profesaba.

${ }^{41} \mathrm{IX}: 282$.
} 
do". ${ }^{42}$ Por eso, en sus últimos años Nishida consideró, siguiendo las tendencias de su época, que toda la ciencia debía ser topológica. ${ }^{43}$

Desde luego, se trata de su propia versión de la topología que tiene siete conceptos fundamentales: 1) el infinito como en Dedekind, que implica recursividad; 2) la continuidad sacádica; 3) conjuntos, grupos, cuerpos y anillos; 4) la topología; 5) dos reglas de transformación: autoidentidad de contradictorios y correspondencia recíproca; 6) la infundamentación (ungrundigkeit);7) el basho de la Nada absoluta que es creativo y en el que Ser=Nada. Es decir, la ciencia debe tener como centro ontológico el topos (basho) de la emergencia de todo lo que es realidad histórica en mutua interdependencia existencial, asubstancial y carente de toda fundamentación. ${ }^{44}$

Hay muchas otras definiciones de [la] ciencia y es discutible la definición operacionalista, pero en sus últimos años Nishida se inclinó por una fundamentación operacionalista que lleva a cabo a su manera. Pone énfasis en que la fundamentación de la filosofía y de toda ciencia debe hacerse desde la operación de la intuición activa en que se descubre el si-mismo total y el mundo histórico a través de la unidad de conocimiento y acción, al estilo de Wang Yang-Ming. ${ }^{45}$ La intuición activa penetra hasta la base de la constitución de todo conocimiento: penetra hasta "el significado de que el basho [topos] se determina a sí mismo". ${ }^{46}$ Desde este punto de vista escribe:

\footnotetext{
${ }^{42} \mathrm{X}: 160$.

${ }^{43}$ Cfr. X: 462.

${ }^{44}$ Véase una manera de interpretar ese basho en mi Filosofía de la transformación del mundo, Parte II, Zamora, El Colegio de Michoacán, 1989, 115-254.

${ }^{45}$ El neoconfuciano Wang Yang-ming (1472-1529) propuso una interpretación alternativa de los cuatro libros y los cinco clásicos del confucianismo. A diferencia del dualismo del neoconfuciano Chu Hsi (1130-1200) en su Chin Ssu-lu, toma como uno de los puntos centrales el no dualismo de conocimiento-acción. La obra que presenta el pensamiento de Wang Yang-ming fue recopilada por sus discípulos, y se llama Ch'uan-hsi-lu. Véase Wing-tsit Chan (trad.), Instructions For Practical Living, Nueva York, Columbia University Press, 1963; véase también el estudio de Antonio S. Cua, The Unity of Knowledge and Action: A Study in Wang Yang-ming's Moral Psychology, Honolulu, University of Hawaii Press, 1982.

${ }^{46}$ VI: 217.
} 
la operación fundamental que es para nosotros la más concreta, debe ser la intuición activa del si-mismo poiético. Allí se da el mundo en el que estamos nosotros, se da el mundo del si-mismo total. Y también todas las ciencias deben fundamentarse aquí. Además, esta operación fundamental es algo que pensamos que es "base de la vida diaria". [...] También la operación fundamental de la filosofía debe ser la "base de la vida diaria". Lo que piensa unificadamente al mundo desde este punto de vista, es la filosofía. ${ }^{47}$

En sus últimos años Nishida consideró que "el método de la ciencia es la intuición activa", ${ }^{48} \mathrm{y}$ en tanto que el hombre se lleva a sí mismo en su propia autonegación el hombre es científico y, en este sentido, la ciencia también es una especie de cultura. ${ }^{49}$ Filosofía y ciencia nunca están desligadas y entre ellas debe haber mutuo respeto:

la filosofía respeta a la ciencia y toma la ciencia como su material; a su vez, la ciencia debe fundamentarse en la filosofía. Pudiera incluso decirse que el propósito de la crítica de que Galileo construyó sin sentar las bases, reside en el requerimiento de una fundamentación metafísica de las nuevas ciencias naturales. Pero eso no significa que confundiendo los puntos de vista de ambos, se introduzca la filosofía dentro de las ciencias. ${ }^{50}$

En 1931, Nishida hace también referencia a la estrecha relación que han tenido la política y la economía con la filosofía, tanto en la antigüedad, como en Adam Smith y en Marx. Afirma que sin una buena comprensión del empiricismo en el caso de uno, y del hegelianismo en el caso del otro, no es posible comprender a fondo su pensamiento económico. ${ }^{51}$ Por eso en 1941 dice que la "base de la vida diaria" es la operación fundamental de la filosofía; de ahí que "la filosofía es el más elevado sentido común y, por otra parte, debe ser la base de las diferentes disciplinas académicas". 52
${ }^{47} \mathrm{IX}: 303$.
${ }^{48} \mathrm{XI}: 156$.
${ }^{49} \mathrm{XI}: 458$.
${ }^{50} \mathrm{XI}: 173$.
${ }^{51}$ XIII: 235.
${ }^{52}$ XIII: 244 . 
Nishida no toma como punto de partida la reflexión sobre el si-mismo, o la duda metódica, o el despejar el sentido común. Como veremos, toma como punto de partida la vivencia del fundamento existencial del hombre y de la realidad. En la vivencia del propio fundamento existencial no hay todavía un si-mismo que pueda reflexionar. Llevar a cabo esa reflexión es tarea de la filosofía. El estudio de la constitución de ese simismo que filosofa es una tarea insoslayable para la filosofía. Nishida considera que el punto de partida, de donde arrancan la filosofía, el arte, la ciencia, y la vida histórica del hombre está en lo que él denomina, utilizando el vocabulario del budismo, "base de la vida diaria" o "base del vivir diario".

Por eso debemos comenzar preguntando: ¿Qué es esa "base de la vida diaria"? Ante todo hay que decir que es aquello a partir de lo cual se constituyen el mundo y el individuo humano dentro del mundo. Éstos se constituyen conjuntamente. Examinar la "base de la vida diaria" es examinar el evento fundante de dicha constitución. Es ver cómo son constituidos el individuo humano y el mundo. Es el punto de vista de la autopercepción del mundo y del individuo humano. Por eso le llama Nishida "autopercepción fundamental". 53

Ese evento fundante es lo más básico y "lo más básico debe ser enteramente la base de la vida diaria". Aunque ese evento fundante es constitución conjunta de mundo e individuo humano eso no quiere decir "que sea una unidad indiferenciada.[...] Debe haber una diferenciación infinita en cuanto uno $=$ todo y todo $=$ uno con carácter de autoidentidad de lo contradictorio. Todo se establece mediante ella" ${ }^{54}$

Allí se requiere un punto de vista que dejando de lado toda objetualización y todo apego al si-mismo individual como substancia, viva en el mundo con carácter de "unidad de cuerpo y corazón". Ese punto de vista implica a su vez que se vea la unidad de realidad presente y realidad total. Nishida le llama también "el punto de vista del instante absoluto", que conlleva una negación absoluta al pasar por la mediación de la Nada absoluta. ${ }^{55} \mathrm{~A}$ su vez, "tomar como mediador a la Nada absoluta
${ }^{53} \mathrm{X}: 123$.
${ }^{54} \mathrm{IX}: 333$.
${ }^{55} \mathrm{X}: 251$. 
debe ser tomar como mediador a la autoexpresión del Uno absoluto". En términos budistas se expresa como "lo natural es ya el Dharma [jinen hôni]". ${ }^{56}$ Es, igualmente, "que el si-mismo se haga punto de autoexpresión del mundo. Es que se convierta en verdadero individuo y se vuelva un verdadero si-mismo" ${ }^{57}$ Esta es la constitución conjunta de mundo e individuo humano.

El punto de vista de la "unidad de cuerpo y corazón" es resultante de la intuición activa del si-mismo poietico, que es la "operación fundamental". En esa operación fundamental "se da el mundo en el que estamos nosotros, se da el mundo del si-mismo total. Y también todas las ciencias deben fundamentarse aquí". En una palabra, la intuición activa del si-mismo poietico como operación fundamental es "base de la vida diaria" ${ }^{58}$

Ya en el volumen I de la Colección de ensayos filosóficos Nishida había escrito sobre la vida cotidiana o la vida diaria. Sin embargo, posteriormente sigue reflexionando y encuentra las dos expresiones del budismo Zen: "base de la vida diaria" $\mathrm{y}$ "mente ordinaria" como aquello que fundamenta a la vida cotidiana o vida diaria y que es el sólido asiento del "si-mismo total" que vive en el mundo histórico. Por eso, antes de hablar de la vida diaria o vida cotidiana, era necesario hablar de esa "base de la vida diaria".

Hay dos malentendidos principales que Nishida quiere evitar: el primero es la confusión de la "base de la vida diaria" con los asuntos cotidianos, y la segunda es la confusión con el sentido común (segundo significado del sensus communis) que conlleva una parte que es doxa. Respecto al primer malentendido, Nishida escribe que no se trata de los asuntos cotidianos sino de la autoidentidad de lo contradictorio entre acción moral y actos cotidianos: esto es la "mente ordinaria". ${ }^{59}$ Nuestras acciones no solamente están en un espacio histórico sino entran en relación directa con el absoluto. Ésta es la oportunidad que tiene el si-mismo de penetrar profundamente en el corazón no-nato del Buda: esa penetración religiosa viene a ser la autopercepción fundamental de la que arranca la filosofía, ${ }^{60} \sin$ que por ello la filosofía deba ser religiosa.

\footnotetext{
${ }^{56} \mathrm{X}: 475$.

${ }^{57} \mathrm{X}: 450$.

${ }^{58} \mathrm{IX}: 303$.

${ }^{59} \mathrm{X}: 122-123$.

${ }^{60} \mathrm{X}: 123$.
} 
El segundo malentendido es confundir la "base de la vida diaria" con el sentido común. Nishida escribe: "lo que aquí llamo 'base de la vida diaria' no debe confundirse con el sentido común. El sentido común no pasa de ser un sistema de conocimiento social hecho históricamente. Es una costumbre que ha tomado forma con carácter de disposición". ${ }^{61}$ Aun así, en el sentido común está incluida esa "base de la vida diaria". Por eso, aunque en el sentido común hay doxa, lo que debe ser negado en el sentido común es "la doxa y no la intuición". ${ }^{62}$ Aquí doxa tiene un significado semejante al de los idola de Francis Bacon (15611626) en su obra Novum Organum (1620): de la tribu, de la caverna, del mercado y del teatro.

Ahora bien, la vida diaria o vida cotidiana en Nishida es la operación fundamental de la intuición activa del si-mismo histórico corporal: se da la "unidad de cuerpo y corazón". Por eso "el si-mismo corporal es el órgano de autodeterminación del mundo". ${ }^{63}$ En tanto que es una corporalidad histórica creativa que mediante la intuición activa determina al mundo y es a su vez determinado por éste. En el mundo de la vida diaria en el que los fenómenos son la realidad y viceversa, nuestra corporalidad histórica es determinación individual del mundo: en el eterno ahora tenemos consciencia que ve y comprende al mundo de expresión infinita, y tenemos libertad infinita en nuestra voluntad. Respecto a la historia y a la ciencia Nishida dice que "también la historia del pasado puede pensarse a partir de aquí. También el pasado está en el eterno ahora. Por otra parte, también el experimento físico se realiza aquí, y los proyectos del futuro se originan a partir de aquí". ${ }^{64}$

Nishida dice que esa base de la vida diaria "es el punto de vista de la autodeterminación del mundo histórico" . ${ }^{65}$ Por eso, "desde el punto de vista de la cultura oriental", el punto de partida está "en lo que se denomina 'base de la vida diaria'". Sin embargo, al hablar del punto de vista de la cultura oriental existe siempre el peligro de la unilateralidad. En ese sentido, el punto de vista de la cultura oriental puede diferir del de

\footnotetext{
${ }^{61} \mathrm{X}: 450-452$

${ }^{62}$ XI: 453.

${ }^{63}$ VIII: 176.

${ }^{64}$ VIII: 177.

${ }^{65}$ XI: 451.
} 
la cultura occidental, pero "la verdad concreta debe ser una" ${ }^{66} \mathrm{y}$ la diferencia puede subsistir sólo mientras no se elimine su unilateralidad. Al final veremos que Nishida es coherente en esta afirmación también en el caso de las características culturales y sociológicas del concepto de ciencia y del conocimiento científico.

Dentro de esta caracterización, es conveniente ver la manera en que Nishida se refiere al problema de una "ciencia japonesa". En 1937, Nishida en "El método científico [académico]", escribió acerca de la "ciencia japonesa" de la siguiente manera:

Hoy todos hablan de que por el espíritu japonés, al aceptar y digerir la cultura occidental, se crea una cultura peculiar del Japón. Y no muchos diferirán de la idea de que debe ser académica. Pero parece que aun entre los intelectuales hay algunos que no entienden lo verdaderamente académico. La gente piensa que así como el espíritu es algo que el hombre utiliza, así también el conocimiento es como una herramienta. Podemos decir que incluso expresiones tales como 'espíritu japonés y conocimiento chino' nos muestran esta manera de pensar. Pero lo académico es algo que tiene un espíritu. Aún las ciencias naturales lo tienen. Lo académico es el hecho de que nuestro espíritu viva dentro de las cosas. De esta manera empezará a haber una ciencia japonesa. En este sentido se habla de las matemáticas inglesas, francesas, alemanas, etc. De no ser así, aunque se le llame espíritu no pasa de ser un concepto abstracto. Las Ciencias del Espíritu aun cuando tengan contenidos diferentes, deben constituirse mediante el hecho de que vivamos dentro de las cosas objetivas históricas. Eso es lo metodológico que antes mencioné. ${ }^{67}$

LO QUE SE VA A CONOCER Y MANERA DE CONOCERLO

Para examinar lo que conoce la ciencia y la manera en que lo conoce, vamos a ver dos aspectos principales. Como resultado de las maneras en que se ha caracterizado la teoría de la realidad en la filosofía de Nishida, se puede hablar de cuatro modelos de la realidad discernibles a lo

\footnotetext{
${ }^{66} \mathrm{X}: 474$.
}

${ }^{67}$ XII: 388 . 
largo de su carrera textual. Esa realidad conceptualmente representada con el objeto de describirla para nuestro entendimiento, habría de ser conocida de una manera característica por una epistemología "oriental". Vamos a ver de manera resumida estos dos puntos.

La ontología en la ciencia: cuatro paradigmas de la realidad

Estoy consciente de que Nishida no consideró sus diferentes maneras de referirse a la realidad como "modelos" en el sentido estricto de paradigmas a partir de los cuales analizar la realidad. Son, más bien, maneras de representar la realidad con el fin de hacerla comprensible para nosotros. Sin embargo, considero que llamarles así tiene también sus ventajas, en cuanto que podemos decir, con Nishida, que son el aspecto de autonegación de la lógica que él trataba de desarrollar: una lógica que fuera autoexpresión logos-ica de la realidad. Además, en el sentido de que se trata de expresiones que van siendo poco a poco perfeccionadas o que son abandonadas por otras, también les podemos llamar paradigmas en sentido lato. ${ }^{68}$

La realidad como sistema autorrepresentativo

La realidad como sistema representativo que se mapea sobre sí mismo. Es un modelo recursivo de la realidad. Esta es la manera en que Nishida presenta la realidad, bajo la influencia de Royce. Principalmente está representado por "La comprensión lógica y la comprensión matemática", donde aparece ya el concepto de infinito en el sentido de Dedekind. El concepto de sistema es también de origen matemático. ${ }^{69}$ Este modelo funciona principalmente entre 1912 y 1914 en el pensamiento de Nishida.

El artículo "La comprensión lógica y la comprensión matemática" que Nishida escribe a poco tiempo de su llegada a Kioto, refleja su pre-

\footnotetext{
${ }^{68}$ Aunque la lógica y la epistemología de Nishida quieren moverse junto con la fluidez de la realidad histórica, la manera en que Nishida en su periodo tardío hace explícita para nuestra comprensión la estructura dialéctica de esa realidad podría describirse como un constructivismo operacionalista capaz de preservar la radical infundamentación de esa realidad (Cf. XI: 359), mientras mantiene un objetivismo radical (XII: 298).

${ }^{69}$ Agustín Jacinto Z., Filosofía de la transformación del mundo, pp. 162-163.
} 
ocupación con las matemáticas. Encuentra que una manera de exponer lo que él quiere decir acerca de la realidad es a través de los conceptos matemáticos. Esto Nishida lo vio claramente cuando leyó la tesis de uno de sus alumnos en la Escuela de Filosofía, Yamanouchi Tokuryû. Nishida pudo darse cuenta de ello, porque él mismo estaba interesado en ese aspecto de la expresión de la realidad. Nishida bajo la influencia del matemático Sono Masazô (a cuyos cursos asistió siendo ya catedrático de la Universidad de Kioto), estudió la teoría de conjuntos y teoría de grupos: y el sistema autorrepresentativo vino a ser paralelo del grupo infinito completo. En ese grupo hay una continuidad que se expresa como continuidad de lo discontinuo. ${ }^{70}$ En muchos de los escritos de Nishida se encuentra este modelo que concibe a la realidad como grupo continuo en transformación permanente. Las matemáticas de este modelo deben ser realmente muy complicadas, si es que alguna vez se llega a intentar su utilización.

Entre 1914 y 1924 se refina este modelo que ya en 1926 concibe como el topos de la Nada absoluta, pero es apenas el esbozo de otro modelo, que veremos un poco después. Este sistema posteriormente, hacia 1934 o 1935 se convierte, al ser refinado por Nishida, en un sistema expresivo que finalmente llega a la autopercepción.

La realidad como sistema autoperceptivo

Inicialmente el concepto de autopercepción viene a ser equivalente al concepto de autorrepresentación según la lectura nishidiana de Royce. Posteriormente bajo la influencia de Fichte, la autopercepción viene a ser resultado de la actividad primigenia del Tathandlung (hecho-acción). De esta manera liga Nishida su pensamiento con la Doctrina de la Ciencia del Conocer $(1794,1801,1804)$ de Johann Gottlieb Fichte. ${ }^{71}$ Después de 1926, con la introducción del concepto del topos fue necesario pensar las relaciones constitutivas en el mismo. El topos como sistema del universal

\footnotetext{
${ }^{70}$ Op. cit.p. 163.

${ }^{71}$ Véase también Immanuel H. Fichte, Das Erkenntnis als Selbsterkennen (El conocimiento como autoconocimiento), Heidelberg, 1833, que es el primer volumen de la obra Gründzuge zum Systeme der Philosophie, consultado como E-book en Gallica N0095392, www.bnf.fr.
} 
incluye relaciones internas que son su autodeterminación: se trata de un universal autodeterminativo. El sistema tiene autorreferencialidad, esto es, es un sistema recursivo infinito (se mapea sobre sí mismo), y dentro de este sistema autodeterminativo se dan los diferentes universales. ${ }^{72}$ Estos universales son nueve o diez y pueden verse principalmente en el volumen v de las Obras completas de Nishida Kitarô. Este modelo es predominante entre 1926 y 1930. Aunque en este modelo se empieza a ver el aspecto de la autoexpresión de la realidad, todavía no es claro.

La realidad como esfera infinita

Sobre todo en el volumen vi de sus obras completas, Nishida toma de Pascal y de Nicolás de Cusa la idea de la esfera infinita en la que todo lugar es centro y ninguna periferia. Esta idea proviene del Liber Viginti Quattuor Philosophorum. ${ }^{73}$ Como dice Alexander Koyré, la idea de una esfera infinita lleva consigo el concepto de múltiples mundos. La pluralidad de mundos contribuyó a echar abajo la idea de un solo mundo al centro del universo. La esfera infinita vino a ser punto de apoyo para concebir la realidad como conjunto de multiplicidades o manyfolds (como lo sugiere Husserl en sus Investigaciones lógicas). De allí que en Nishida se transforme esta idea en un modelo de la realidad como realidad matricial. Esa realidad matricial es de múltiples presentes en diferentes curvaturas de la realidad histórica. El presente es multifoliar, es decir, se determina de diversas maneras en los diferentes mundos particulares que marcan las múltiples líneas del mundo. Este modelo tiene su inspiración en la física moderna y aunque implica un cálculo matricial (relatividad general, mecánica cuántica y mecánica ondulatoria), fue utilizado conceptualmente por Nishida en el periodo de 1930 a 1934.

En este modelo Nishida plantea por primera vez el problema de la autoexpresión de la realidad autoformativa. Comienza con la consideración de los problemas epistemológicos que ello trae consigo:

\footnotetext{
${ }^{72}$ Agustín Jacinto Z., op. cit. p. 163.

${ }^{73}$ Definición 2: "Deus est sphaera infinita cuius centrum est ubique, circumferentia nusquam". Véase sitio del Corpus Christianorum.
} 
Nuestro conocimiento comienza a partir de la determinación del yo mismo como sum; nuestro conocimiento no comienza de la percatación objetual sino del 'hecho' como contenido de la autodeterminación del topos mismo. Lo que puede ser pensado verdaderamente como 'hecho' - en cuanto contenido del ahora que se determina a sí mismo- tiene el significado de contenido expresivo del antes de la separación entre sujeto y objeto. ${ }^{74}$

Luego avanza hasta dejar claramente planteado el problema de que todas las cosas históricas son expresivas, la materia es expresiva y la realidad entera es autoexpresiva. Así nos dice: "lo objetivo viene a ser lo que simplemente se expresa a sí mismo". ${ }^{75} \mathrm{El}$ planteamiento está directamente ligado al concepto de la esfera infinita, ya que "desde el punto de vista que incluye al movimiento dialéctico, se puede pensar en dirección noetica algo como la voluntad libre y, al mismo tiempo, en su dirección noemática, puede pensarse algo como el simple mundo de la expresión en cuanto contenido del aspecto de determinación de la esfera que no tiene centro". ${ }^{76}$

El mundo de la expresión viene a ser un punto central de la exposición que gira alrededor de la esfera infinita. Nishida dice que "cuando pensamos que el si-mismo activo se pierde a sí mismo, es decir, cuando pensamos que el centro de la vasta esfera infinita que tiene un centro es borrado por el aspecto que niega al centro, [entonces] se constituye algo como el mundo de la expresión en cuanto autodeterminación de la esfera sin centro. [...] la esfera sin centro viene a ser algo como el campo de expresión que se piensa que es no-autoperceptivo". ${ }^{77}$

Cuando la expresión deja de ser sólo manifestación en el campo de la consciencia del si-mismo, y viene a ser característica de toda la realidad, Nishida alcanza una nueva manera de ver la realidad: en el mundo histórico todo es expresivo. Aunque Nishida lo utiliza principalmente para su posterior discusión con los marxistas y su concepto de la materia, esta realidad autoexpresiva viene a ser un problema nuevo

\footnotetext{
${ }^{74}$ VI: 175.

${ }^{75}$ VI: 199.

${ }^{76}$ VI: 208-209.

${ }^{77}$ VI: 209-210.
} 
cuando se le considera desde el punto de vista de la filosofía de la ciencia. Esta característica de la realidad permea todo el pensamiento posterior a 1930 de Nishida.

La realidad como grupo topológico infinito

Aquí quiero hacer referencia a las diez raíces del topos: a) El chora de Platón; b) El to hen de Plotino; c) El topos de Aristóteles; d) La Gebietskategorie de Emile Lask; e) El phänomenales Feld y el somatisches Feld de Wolfang Köhler, de la escuela Gestalt; f) El Bewusstseinsfeld de Husserl; g) El topos del analysis situs de Poincaré; h) La Feldtheorie de Maxwell; i) El field de Kurt Lewin;j) El absolutes Nichts-platz. En otra ocasión presenté estos elementos de este basho de la Nada absoluta. ${ }^{78}$ No todas estas raíces están presentes en el modelo del grupo infinito antes mencionado. Poco a poco Nishida va perfeccionando este modelo y es notable la inclusión de la topología psicológica de hace Kurt Lewin.

Para expresar las relaciones topológicas, Nishida utiliza una serie de conceptos que expresan (según mi interpretación) dos aspectos fundamentales: 1) el aspecto de unidad de la realidad, que en un principio se expresó como unidad de opuestos y después como autoidentidad de lo contradictorio; 2) el aspecto de diversidad, de multiplicidad de los elementos de esa realidad, que se expresó de diferentes maneras; i) como mutua determinación entre elementos dentro de la autodeterminación del universal; ii) que luego se convierte en determinación recíproca; iii) luego se especifica como correspondencia mutua entre elementos; $\mathrm{y}$ iv) finalmente viene a ser la correspondencia recíproca. Mediante estas dos relaciones topológicas se construye la topología de la infundamentación. Es decir, la construcción del modelo de la realidad sobre un topos sin coordenadas de origen. Es un topos metamórfico, en el que se da la originación interdependiente (pratitya samutpâdâ) como expresión budista de la Nada absoluta (sunyatâ). ${ }^{79}$

\footnotetext{
${ }^{78}$ Agustín Jacinto Z., "Tradition and the Problem of Knowledge in Nishida Philosophy" en Dokkyô International Review, Sôka-shi, Saitama-ken, Japón, núm. 14, 2001, 91-135.

${ }^{79}$ Puede verse una exposición resumida de las características de los elementos de este modelo en la Conclusión general de mi libro Filosofía de la transformación del mundo, pp. 399-404.
} 
De allí resulta un modelo de la realidad que es el de un mundo en flujo constante y sin ninguna fundamentación. En algún sentido podría decirse que es semejante a la visión de la realidad que William James propone en su obra Pragmatismo, que originalmente llevaba el subtítulo de Un nuevo nombre para algunos viejos modos de pensar (1907), aunque eso no quiere decir que Nishida retome punto por punto las ideas de James.

Para percibir mejor el parecido, veamos lo que dice William James. La manera de ver la realidad en el pragmatismo se caracteriza por:

a) "rompemos en cosas el flujo de la realidad sensible, según nuestra voluntad. Creamos los sujetos tanto de nuestras proposiciones verdaderas como de las falsas;

b) "creamos también los predicados. Muchos de los predicados de cosas expresan solamente las relaciones de las cosas con nosotros y nuestros sentimientos"; 80

c) "de una cosa en otra aunque permanezca el hecho bruto de que existe un flujo sensible lo que es cierto de ello parece, desde el principio al fin, una exclusiva creación nuestra;

d) "inevitablemente, creamos el flujo" ${ }^{81}$ En resumen, la realidad "para el pragmatismo está aún haciéndose y espera del futuro parte de su estructura" ${ }^{82}$

De aquí resulta la infundamentación restringida al sistema de conocimiento:

e) "para el pragmatismo pluralista la verdad se desenvuelve dentro de toda experiencia finita. Se apoyan unas en otras, pero el conjunto de ellas, si existe tal conjunto, no se apoya en nada. [...] Nada fuera del flujo asegura su existencia. [...] Para los racionalistas esto representa un mundo vagabundo y errante, flotando en el espacio, sin ningún elefante ni tortuga en que apoyar sus pies. Es una serie de estrellas clavadas en el cielo, incluso sin centro de gravedad hacia el que tender" ${ }^{\prime \prime 3}$

\footnotetext{
${ }^{80}$ William James, Pragmatismo[1907] Madrid, SARPE, 1984, 203.

${ }^{81}$ Op.cit.p. 204.

${ }^{82}$ Op. cit.p. 205.

${ }^{83}$ Op. cit. pp. 207-208.
} 
f) De manera más específica, señala la ausencia de un trasfondo fundante de los fenómenos: "detrás de los hechos fenoménicos, [...] no hay nada" ${ }^{84}$

De allí nos resulta el panorama de un mundo, de una realidad finitista: en flujo, imperfecta, sin fundamento y sin apoyo alguno. No se trata de una realidad infinitista: acabada, perfecta y fundamentada. ${ }^{85}$ Nishida leyó esta obra ${ }^{86} \mathrm{y}$ algunos de los autores que cita James son también de los que cita Nishida, ${ }^{87}$ y además se declara "positivista radical" ${ }^{88}$

Este flujo infinito de la realidad, nos lleva a Heráclito. ${ }^{89}$ Nishida, que había leído también los Fragmentos de los presocráticos, fácilmente puede también elaborar su propia interpretación de ese pensador.

Nishida basa su heracliteanismo en los siguientes puntos:1) Apolo no se revela abiertamente sino que se oculta y se da a conocer por signos; 2) La realidad es autoexpresiva, tiene carácter de $\log o s ; 3)$ Polemos es el padre de todas las cosas; 4) Todo es uno, y hay mutua transmutación entre contradictorios; 5) Nada queda y todo fluye: no hay referentes de origen, todas las coordenadas se determinan en la corporalidad del foco autoformativo de la realidad. Esa realidad heracliteana o "mundo heracliteano ${ }^{\prime \prime 90}$ viene a ser una realidad dialéctica que tiene también cinco características: es a) autonegativa, b) autodeterminativa, c) autoafirmativa, d) autoexpresiva, y e) autoformativa.

Mediante este grupo topológico infinito en transformación continua y sacádica, puede verse la impermanencia, la asubstancialidad y la infundamentación de la realidad histórica en la que todo subsiste en mu-

${ }^{84}$ Op. cit. p. 209.

${ }^{85}$ Cf.op. cit. p. 211.

${ }^{86}$ XIV: 71.

${ }^{87}$ Por ejemplo, encontramos que en la Segunda Conferencia, James cita el artículo "How to make our ideas clear" que Charles Sanders Peirce publicó en enero de 1878 en el Popular Science Monthly, James, op. cit. p. 61.

${ }^{88}$ XI: 45; cf. 124, 292.

${ }^{89}$ Por eso Nishida habla de su propia "dialéctica realista heracliteana". IX: 97.

${ }^{90}$ VIII: 516. También lo describe como un "mundo dialéctico -de lo múltiple y lo uno-heracliteano". IX: 107. 
tua dependencia existencial. Su idea metafísica tardía fue la unión de los mundos heracliteano y platónico en uno. ${ }^{91}$

Estos son algunos de los modelos de la realidad que encontramos en Nishida delineados con alguna claridad. Pudieran encontrarse otros. Nishida mismo se inclinó por los modelos matemáticos para la fundamentación de las ciencias. Se ocupó en la reflexión sobre el surgimiento de las ciencias naturales y de las ciencias sociales ciencias en sus últimos años, cuando estaba por completar el modelo del topos infundamentado, que fue el que parece haberle resultado más satisfactorio.

Para una epistemologia "oriental" de Nishida

No voy a hacer un examen detallado de la epistemología de Nishida en su periodo tardío. Esta es una tarea que aun está por hacerse. Aquí sólo tocaré algunos aspectos que están más específicamente ligados al tema de una "ciencia japonesa", para hacer resaltar el aspecto "oriental" o japonés de la epistemología de Nishida.

El examen de los modos de contacto con la realidad, el proceso de su conocimiento y la organización de ese conocimiento para la vida del hombre son tres de los principales objetivos de la epistemología. Al respecto, encontramos en la epistemología nishidiana algunos rasgos que le son característicos.

La corporalidad histórica

Nuestro contacto con la realidad es ante todo un contacto corporal. La realidad se manifiesta en nosotros como cuerpo nuestro y como mente nuestra, y nosotros nos encontramos con ella mediante nuestro cuerpo. Nishida dice que "lo sensorial tiene un significado corporal". ${ }^{92}$

Cuando entramos en contacto corporalmente con la realidad, ello significa que la realidad entra en un nuevo orden, adquiere una nueva morfología dentro de las coordenadas corporales de nuestro si-mismo.

${ }^{91}$ IX: 109. Esa unión se realiza mediante la poiesis técnica del hombre en la realidad histórica.

${ }^{92}$ VI: 129. 
Con ello se transforma la racionalidad de la realidad y adquiere el carácter de naturaleza: en la naturaleza estamos tanto nosotros como las cosas. Podría incluso decirse que lo irracional se hace racional en su contacto con el si-mismo activo: en el contacto de lo irracional con nuestro cuerpo, mente y sentimientos creamos nuestro ambiente. ${ }^{93}$ Eso que consideramos irracional y que está en el fondo de nuestra corporalidad es algo que nos da muerte y nos da origen. ${ }^{94}$

Nishida dice que nuestra vida real es corporal y sin cuerpo no hay vida. ${ }^{95}$ Nos determinamos a nosotros mismos en la naturaleza y mediante ésta. ${ }^{96} \mathrm{El}$ cuerpo es el lugar donde se tocan los aspectos de vida y de muerte. ${ }^{97}$ Pero ese cuerpo nuestro no es simple materia objetual, inexpresiva e inerte sino algo que es activo:98 además de ser materia expresiva, tiene un significado histórico social. ${ }^{99}$ Aunque tiene un aspecto instrumental, tiene otro que es expresivo: "el cuerpo frecuentemente se piensa como simple órgano del comportamiento, pero sin cuerpo no hay si-mismo: el cuerpo no solamente tiene el significado de existencia misma del si-mismo sino que tiene el significado de [ser] su expresión" ${ }^{100}$

Valorando la importancia que tiene la corporalidad en Nishida, en Filosofía de la transformación del mundo y en La filosofía social de Nishida Kitarô comencé la exposición desde la corporalidad. Por eso aquí no voy a repetir otros aspectos que allí pueden leerse. Sin embargo, en la epistemología es también necesario comenzar por la corporalidad. Esto se debe a la posición central que tiene el cuerpo histórico en la filosofía tardía de Nishida, y a que en el caso de un realismo como el que Nishida sostiene, la vivencia es principio de conocimiento. ${ }^{101}$

Lo más importante en relación con el carácter oriental o japonés del concepto de corporalidad es que Nishida no lo separa de la mente, no lo

\footnotetext{
${ }^{93} \mathrm{VI}: 367$.

${ }^{94} \mathrm{VI}: 375$.

${ }^{95} \mathrm{VI}: 360$.

${ }^{96} \mathrm{VI}: 212$.

${ }^{97}$ VI: 202.

${ }^{98} \mathrm{VI}: 316$.

${ }^{99}$ VI: 372.

${ }^{100}$ VI: 72.

${ }^{101}$ VIII: 99.
} 
separa de la naturaleza, no lo separa del mundo y en que lo concibe como histórico y expresivo. En este sentido, el cuerpo histórico es "órgano de la ciencia".

Koiné aisthesis

El aspecto más importante en relación con la manera oriental y, más específicamente, japonesa de concebir la percepción es aquella que se relaciona con las artes derivadas del budismo, especialmente las artes marciales.

Basándose en la manera en que se describe el proceso de la percepción en algunos de los textos budistas, se habla de ver con todo el cuerpo, de percibir con todos los sentidos al mismo tiempo, de una audición dermal, etcétera. En los libros de Alan Watts, Suzuki Daisetz, Deshimaru Taisen, etcétera, o libros sobre Tai-chi, se encuentra esta manera de describir la percepción.

En su periodo tardío (1930-1945), Nishida llegó a formular este aspecto de la percepción recurriendo al término aristotélico koiné aisthesis (el escolástico sensus communis), pero difiere por completo en la interpretación del término. En el caso del sistema aristotélico-tomista, se refiere a aquella función del intelecto pasivo que recibe y procesa los "fantasmas" que provienen de la percepción individual de cada uno de los cinco sentidos. Una vez que ese sensus communis entra en acción, se hace notable la acción del intelecto activo, que de allí abstrae la "forma" metafísica de los objetos percibidos.

En el caso de Nishida el koiné aisthesis (kyôtsû kankaku), es una manera privilegiada de la percepción, resultado de un largo entrenamiento, y que lleva consigo una manera de ser cuerpo diferente de la del intelectualismo aristotélico-tomista y que consiste en una percepción sensorial unificada. Entre sus características podemos mencionar las siguientes:

a) el entrenamiento de la corporalidad: ya sea por las artes budistas, por otras artes marciales, por la meditación Zen, por la entrega corporal total a la recitación del Nombre Maravilloso del Buda, etc.; b) todo el cuerpo, su estructura y su función se activan de manera especializada que se manifiesta en su "forma" o condición entrenada; c) 
la capacidad de activar cualquiera de los sentidos en la corporalidad entera: todo lugar de la esfera infinita que es el cuerpo viene a ser centro de actividad de uno cualquiera de los sentidos: todo el cuerpo es vista, todo el cuerpo es oído, todo el cuerpo es gusto, es tacto, es olfato. Hasta aquí llegaron los teóricos de la espada como Takuan Zenji; d) el cuerpo viene a ser órgano del pensar y esto sería comparable a decir que el pensamiento es de inmediato sensibilidad, etc. como desearía T. S. Eliot; e) con ello la actividad perceptiva viene a ser autoexpresión de la realidad histórica. ${ }^{102}$

Hay una teoría de la percepción que podría en cierta medida ser la contraparte: es la teoría Gestalt o holista de la percepción. Sin embargo, mientras que en el caso de la teoría de la percepción de Nishida es todo el cuerpo el que se convierte en cada uno de los sentidos y el cuerpo mismo como parte de una realidad histórica expresiva viene a ser órgano del pensar, en la teoría Gestalt se enfatiza la unidad de lo percibido y se engloba percipiente y percibido en una totalidad.

Nishida ciertamente había leído las obras de Wolfgang Köhler -que maneja el concepto de morfología de los fenómenos 'espirituales', en la que destacan el somatisches Feld y su phänomenales Feld $-{ }^{103}$, Karl Bühler, Christian von Ehrenfels, Kurt Koffka y Max Wertheimer. La influencia de la Gestalt sobre Nishida es fuerte entre 1925 y 1930 aproximadamente.

Sin embargo, la forma especializada de condición corporal-mental, que puede verse también como forma de la "actividad natural" como en el Tai-chi, es la que subyace a la teoría de la percepción de Nishida. Es de origen eminentemente budista y está presente en muchos aspectos de la vida cultural oriental y, específicamente, japonesa.

${ }^{102}$ Véase Agustín Jacinto Z. "La misión de la filosofía en Visible et Invisible de Merleau-Ponty" en México, IтAм, Estudios: filosofía/ historia/ letras, núm. 17, verano 1989, 25-49.

${ }^{103}$ Itô Kichinosuke, Iwanami tetsugaku shô-jiten (Pequeño Diccionario de Filosofía de [la Editorial] Iwanami). Tokio, Iwanami shoten, 1949, 393-394. 
El papel de las identidades

Para dar otra idea de los aspectos epistemológicos en que puede verse algo que tiene su origen en la tradición del budismo o, por lo menos, en el pensamiento oriental, vamos a ver el papel de las identidades. Con anterioridad traté este tema desde su aspecto lógico en Filosofía de la transformación del mundo, pero aquí quiero hacer algunos comentarios sobre su importancia en la teoría del conocimiento de Nishida.

Quiero mencionar algunas de las identidades, para que el lector pueda formarse alguna idea. Encontramos en los textos de Nishida afirmaciones tales como "afirmación = negación, negación = afirmación", ${ }^{104}$ "individuo=universal"; $; 105$ "subjetivo= objetivo y objetivo=subjetivo"; 106 "muerte $=$ vida", ${ }^{107}$ "percepción interna= percepción externa"; $; 108$ "presente $=$ pasado" $; 109$ "individuo $=$ universal y universal $=$ individuo" $; 110$ "lineal = circular y circular = lineal";,111 "consciencia = realidad"; ;12 "determinación interna $=$ determinación externa y determinación externa $=$ determinación interna"; ;13 "múltiple= uno y uno= múltiple"; 114 "dentro $=$ fuera y fuera $=$ dentro"; 115 "trascendencia $=$ inmanencia e inmanencia $=$ trascendencia", 116 "tiempo = espacio y espacio = tiempo"; ;17 "tiempo interno $=$ tiempo externo y tiempo externo $=$ tiempo interno"; 118 "aspecto del tiempo abstracto $=$ aspecto del tiempo consciente"; $; 11$ "continuidad=
${ }^{104}$ VIII: 32.
${ }^{105}$ VIII: 22.
${ }^{106}$ VIII: 27.
${ }^{107}$ VIII: 28.
${ }^{108}$ VIIII:36.
${ }^{109}$ VIII: 50.
${ }^{110} \mathrm{VIII}: 73$.
${ }^{111}$ VIII: 91.
${ }^{112}$ VIII: 100
${ }^{113}$ VIII: 110
${ }^{114} \mathrm{VIIII}: 111$.
${ }^{115}$ VIII: 112
${ }^{116}$ VIII: 115 .
${ }^{117}$ VIII: 116
${ }^{118}$ VIII: 120
${ }^{119} \mathrm{Ibid}$. 
discontinuidad, discontinuidad $=$ continuidad"; $; 120$ "Nada $=\mathrm{Ser}^{\prime \prime} ;{ }^{121}$ etc. etc. Aquí solamente he mencionado las identidades que aparecen en las primeras 150 páginas del primer volumen de los siete que tiene la Colección de ensayos filosóficos.

Hay muchas otras identidades. Una de sus principales características es que son ciertas también en sus recíprocos. Es decir, tanto del lado izquierdo hacia el derecho como del lado derecho hacia el izquierdo. Si aparecieran esporádicamente, se podría pensar que fueran una ocurrencia de Nishida. Pero en realidad son tantas y se repiten tantas veces que crean un ambiente de pensamiento, un acercamiento a la reflexión filosófica y una manera de dar sentido a los diferentes aspectos del conocimiento. Casi siempre estas identidades van adjetivadas y se les traduce con un circunloquio: "con carácter de...". Es decir, denotan condiciones en las que se dan otros aspectos de la vida humana, son la plataforma, la trama en la que se entreteje el hilo de la vida en la realidad histórica.

La aplicación de la regla de transformación que en los textos nishidianos aparece como "autoidentidad de lo contradictorio", o "autoidentidad contradictoria", en el aspecto epistemológico nos describe una manera de acercarse a la realidad, de entrar en contacto con ella y de vivir corporalmente en ella. En lugar de solamente establecer las diferencias entre nuestro cuerpo y el resto de la realidad, en lugar de establecer los límites del si-mismo corporal, por esta regla de transformación hay una visión unitaria, un holismo que fundamenta y da origen a las posibles diferenciaciones. En lugar de ir desde una visión originalmente fragmentada, disjunta einconexa hacia una visión unificada, conjunta y conexa, partimos de ésta hacia aquélla.

Esto no implica que simplemente se confundan o mezclen los contradictorios, ya que una segunda regla es la "correspondencia recípro$\mathrm{ca}^{\prime \prime}$, en la que cada uno de esos contradictorios se mantiene como tal y nunca pierde su carácter. De esta que se puede dar lo que Nishida denomina "continuidad de la discontinuidad", es decir, una continuidad topológica, que también se describe como continuidad sacádica.

\footnotetext{
${ }^{120}$ VIIII: 124.

${ }^{121}$ VIII: 149.
} 
La intuición activa

Las identidades de cosa $=$ razón [ri],${ }^{122} \cos a=$ acción, ${ }^{123} \cos a=$ conocer, ${ }^{124} \mathrm{y}$ "cuerpo y corazón son uno", 125 no forman un silogismo. Estas identidades son válidas también en sus recíprocos, como ya antes se dijo. Más bien son el trasfondo de lo que en Bergson es penetrar dentro de las cosas y allí hacerse uno con ellas. Sin embargo, según Nishida nos hacemos cosa y, habiéndonos convertido en cosa, pensamos; nos hacemos cosa y, habiéndonos convertido en cosa, actuamos. Además, a diferencia de Bergson, Nishida no olvida que este hacernos cosa se da socialmente: "en la praxis social... conocemos mediante un haciéndonos socialmente cosa, ver y actuar". ${ }^{126}$ En uno de sus aspectos, la intuición es la "autopercepción de la acción" ${ }^{\prime 27}$ y es siempre activa.

Las características de la intuición activa se mencionan en Filosofía social de Nishida Kitarô y se analizan en el segundo capítulo de la I parte de Filosofía de la transformación del mundo. Aquí solamente diré que la intuición activa: a) se da siempre en una situación histórica concreta; b) se da siempre en unidad de toda la consciencia (intelecto, sentimiento, voluntad, etc.); c) es hacernos cosa socialmente, y habiéndonos tornado socialmente cosa, es pensar y actuar también socialmente; d) es un proceso infinito; e) es un proceso dialéctico; f) es un proceso multiforme que no se da de una sola vez; g) es aprehensión corporal de las cosas en el mundo histórico-social; $\mathrm{h}$ ) no es inmediatamente conocimiento organizado; i) es manifestación de la verdadera personalidad del hombre; j) y es creativa.

En este sentido, la intuición activa es un gyô, es decir, es la acción de un cuerpo que lleva en sí mismo la vivencia de su propio fundamento existencial y es "la acción creativa que brota de 'un corazón suave y flexible"'. ${ }^{22}$ Es decir, "es acción celestial del si-mismo que ha dejado caer

\footnotetext{
${ }^{122} \mathrm{X}: 414 ; \mathrm{XI}: 171$.

${ }^{123} \mathrm{X}: 51,382$.

${ }^{124} \mathrm{X}: 369$.

${ }^{125} \mathrm{IX}: 334$.

${ }^{126} \mathrm{X}: 323$.

${ }^{127} \mathrm{VI}: 207$.

${ }^{128}$ XII: 344.
} 
cuerpo y corazón". Este es el aspecto de la intuición activa que lo coloca directamente dentro de la tradición oriental, específicamente del budismo y la iluminación (satori) del Zen. El "dejar caer cuerpo y corazón" describe la condición de liberación total en la vivencia de la iluminación, y el "corazón suave y flexible" nos describe la manera en que el maestro zen Dôgen la expresó cuando en alguna ocasión se le preguntó qué había traído de China en su estudio del budismo Zen. Como dice Nishida: "el meollo del espíritu oriental debe ser, por el contrario, como espíritu japonés: 'la simplicidad incomplicada' con caracter de 'unidad de cuerpo y corazón'”. ${ }^{129}$

Nishida relaciona directamente la intuición activa con la constitución del conocimiento científico y por eso dice que "en la constitución del conocimiento científico debe primeramente estar el punto de vista de la intuición activa". ${ }^{130}$

\section{El conocimiento}

Nishida nos dice que "conocemos en cuanto individuos que están en el mundo histórico" ${ }^{131}$ como expresión de nuestra vida histórica: "nuestra vida histórica es ir construyendo un mundo individualmente. Nuestro conocimiento no es otra cosa que esta actividad constructiva". El conocimiento concreto es la actividad constructiva que "va construyendo un mundo individualmente", ${ }^{132}$ es decir, "nuestro conocimiento se constituye mediante el hecho de que nuestro si-mismo exprese individualmente al mundo y, conversamente, mediante el hecho de que el mundo se autoexprese en el si-mismo en cuanto que éste es autoexpresión del mundo". ${ }^{133}$ El conocimiento concreto "se basa en la intuición activa y tiene carácter de fabricación": $: 134$ es "expresión, con carácter de logos, de la realidad" ${ }^{135}$ En este sentido, nuestro conocimiento se constituye

\footnotetext{
${ }^{129} \mathrm{X}: 159$.

${ }^{130} \mathrm{XI}: 155$.

${ }^{131}$ VIIII: 542.

${ }^{132}$ VIIII: 569.

${ }^{133} \mathrm{XI}: 83-84$; VIII: 454.

${ }^{134}$ VIII: 569.

${ }^{135}$ VIIII: 245.
} 
"mediante la autodeterminación dialéctica del mundo del logos, o bien, mediante la determinación logos-ica del mundo dialéctico".${ }^{136}$ En pocas palabras, "el conocimiento concreto debe ser construcción de la realidad histórica". ${ }^{137}$

Al hablar de conocimiento Nishida no lo restringe como algunos epistemólogos occidentales al conocimiento objetual, que se preocupa por las cosas conocidas olvidando al cognoscente. ${ }^{138}$ Por eso Nishida dice que "nuestro conocimiento no se origina simplemente del mundo de las cosas ni tampoco simplemente del mundo del si-mismo. Utilizando términos usuales puede decirse que se origina en la mutua determinación de sujeto y objeto" ${ }^{139}$ El conocimiento se da en la unión de mente y cuerpo: "el conocimiento científico no se constituye simplemente a partir del punto de vista de un si-mismo abstracto y consciente... [sino] desde el punto de vista de un si-mismo corporal". ${ }^{140}$

Además, el conocimiento tiene un origen social. No es algo que se dé sin una tradición y sin una comunidad. Conocemos "mediante la praxis social. [...] Conocemos mediante el hecho de ver y actuar haciéndonos socialmente cosa". ${ }^{141}$

Los principales tipos de conocimiento que Nishida menciona son:

a) el conocimiento por el sentido común (que tiene validez por tener como base la intuición, aunque conlleva el balasto de la doxa); b) el conocimiento científico, que es el que aquí nos interesa; c) el conocimiento artístico; d) el conocimiento filosófico; y e) el conocimiento religioso.

En esto el único punto notable es el reconocimiento del aspecto de validez en el sentido común, cuya negación ha venido a ser una constante cuando se le contrasta con el conocimiento científico. Generalmente se dice que hay que rechazar el sentido común para acceder al conocimiento científico. Nishida no lo hace. Encuentra que también en el sentido común está funcionando la intuición activa, aunque se encuentre mezclada con la opinión sin fundamento, la proyección y la ilusión.

\footnotetext{
${ }^{136}$ VIIII: 262.

${ }^{137}$ VIII: 542

${ }^{138} \mathrm{XI}: 150$.

${ }^{139} \mathrm{XI}: 154$.

${ }^{140} \mathrm{XI}: 418$.

${ }^{141} \mathrm{X}: 323$.
} 
Nishida escribe que en la ciencia "partiendo de la actividad del cuerpo se debe pasar por la técnica". ${ }^{142}$ Aunque es muy importante en la producción del conocimiento científico, dejaremos para otra ocasión la discusión de la relación que hay entre ciencia y técnica. Por ahora sólo me queda referirme al capítulo titulado "La poiesis técnica" en mi libro Tradición y mundo histórico en la filosofía de Nishida Kitarô donde, junto con el capítulo que le precede se da la debida importancia a este aspecto del conocimiento como construcción del mundo. ${ }^{143}$

Para terminar esta sección sobre el conocimiento vamos ahora a señalar la manera en que ese concepto tiene un fuerte aspecto oriental y japonés.

En primer lugar, Nishida pone como la esencia del "espíritu japonés" y como el punto en que coinciden la etnicidad, la ciencia, la religión y el arte, en ir directamente a las cosas. Allí está la base oriental, japonesa, del conocer. Por eso menciona que "como dice Motoori Norinaga en la obra Naobi no mi-tama (Los dioses de Naobi): 'es solamente ir por el camino que va a las cosas', que debemos entender en el sentido de ir directamente a la realidad de las cosas" ${ }^{144} \mathrm{O}$ en una expresión tradicional: es "seguir la realidad de las cosas negándose a sí mismo". ${ }^{145}$

En segundo lugar, Nishida invoca a Rinzai para decir que allí donde está el si-mismo que es absolutamente libre, dondequiera que esté el "hombre sin título alguno" ${ }^{146}$ que vive en actividad total, ${ }^{147}$ allí todo es verdad. ${ }^{148}$

En tercer lugar nos dice que el conocimiento se da sobre la plataforma de que se llama "base de la vida diaria" que, como ya antes se dijo, es una expresión budista que "expresa el punto de vista de la 'verdadera

\section{${ }^{142}$ IX: 238.}

${ }^{143}$ Agustín Jacinto Z., Tradición y mundo histórico en la filosofía de Nishida Kitarô, Zamora, El Colegio de Michoacán, 2004, 351-413.

${ }^{144}$ XII: 279. Sey Nishimura, "The Way of the Gods. Motoori Norinaga's Naobi no Mitama" en Monumenta Nipponica, Tokio, Sophia University, vol. 46, núm. 1, primavera de 1991, 21-41.

${ }^{145}$ XII: 280.

${ }^{146}$ XI: 432.

${ }^{147}$ XI: 424.

${ }^{148}$ XI: 449. 
voluntad libre'". ${ }^{149}$ Es la "autoidentidad de lo contradictorio", que se mencionó en la sección sobre el papel de las identidades.

Un cuarto rasgo que nos apunta al carácter oriental y japonés del concepto de conocimiento en Nishida, es el criterio de verdad del conocimiento. Ese criterio descansa, no en la coincidencia de "cosa e intelecto", ni en que el conocimiento sea una copia fiel de la realidad, ni en que en la mente se refleje la realidad sociohistórica. Más bien, Nishida nos dice que el conocimiento es verdadero cuando es "atestiguado en los diez mil dharmas". Esta expresión proviene del Shôbôgenzô del maestro zen Dôgen, ${ }^{150}$ y se refiere a la experiencia de la iluminación, cuando se da la realización el kôan. Nishida escribe:

desde mi punto de vista conocer la verdad es mirar el evento de que nuestro si-mismo realmente se autodetermina en cuanto autodeterminación del presente absoluto. La verdad es alethes. Esto es que el si-mismo sea atestiguado en los diez mil dharmas. Esto es lo que yo expreso como 'haciéndose cosa, ver'.[...] Por esto digo que el si-mismo expresa al mundo y al mismo tiempo es un centro de la autoexpresión del mundo. Ahí nuestro si-mismo es intuitivo- activo. ${ }^{151}$

Nishida explica el testimonio de la siguiente manera: "se dice que 'conocerse a sí mismo es olvidarse de sí, olvidarse de sí es ser atestiguado en los diez mil dharmas'. El hecho de que yo diga que mediante nuestro testimonio autoperceptivo se de el proceso de autoexpresión del mundo significa que se dé forma epistemológica a la intuición activa [que es] dinámica". ${ }^{152}$ Cuando el elemento creativo de un mundo creativo, en cuanto que es su foco autoformativo, se coloca en el punto cero del eje de las coordenadas de ese mundo, llega al conocimiento. Esto significa que al colocarse en el campo cero, viene a ser: a) punto de autoproyección del mundo y del absoluto; y b) punto de autoformación

\footnotetext{
${ }^{149} \mathrm{XI}: 451$.

${ }^{150}$ Dôgen Zenji, Shôbôgenzô. The Eye adn Treasury of the True Law, Traducción de Kôsen Nishiyama, Tokio, Nakayama Shobô, 1988, 1. Modifiqué la traducción siguiendo el original en japonés.

${ }^{151} \mathrm{XI}: 70$.

${ }^{152} \mathrm{XI}: 74$.
} 
del mundo y de sí mismo. No sólo es el "punctum saliens aller Lebendigkeit" de Hegel ${ }^{153}$ sino el "erzeugender Punkt" de que habla Cohen. ${ }^{154}$

LA MANERA EN QUE ESTUDIA LA CIENCIA

Aunque al conocimiento de la realidad puede llegarse de diversas maneras, la ciencia tiene una manera característica de estudiar la realidad. A esto es a lo que se le llama el método científico. Vamos a ver a grandes rasgos en las cuatro secciones que siguen lo que Nishida nos dice acerca de la organización del conocimiento, acerca del carácter general del método científico, acerca del carácter de la ciencia en general, y acerca de la universalidad de la ciencia.

\section{La organización del conocimiento}

Desde 1912 Nishida se preocupó por poner a la consideración de los especialistas en ciencias naturales que el método de éstas no es el único método científico. ${ }^{155}$ En los años siguientes Nishida retoma el tema en repetidas ocasiones, especialmente en aquellos escritos que se relacionan con la epistemología. Poco a poco va dejando en claro que cada uno de nosotros llega a ser punto de autoproyección de la realidad de diversas maneras y mediante nuestra intuición activa damos expresión a la realidad mientras trabajamos en su construcción.

La organización del conocimiento que tenemos de la realidad se hace desde un punto de vista que debe ser clarificado. Nishida nos dice que para organizar ese conocimiento se hacen necesarias principalmente cinco operaciones:

a. Diferenciar. La realidad misma se va diferenciando. Pero cuando se establece un punto de vista específico, entonces es necesario delimitar las vecindades del topos de la realidad. Cada ciencia es determi-

\footnotetext{
${ }^{153}$ III: 176.

${ }^{154}$ III: 94, 112, 310, 406, 478 .

${ }^{155} \mathrm{I}: 203-204$.
} 
nación de un punto de vista específico y por ello introduce una diferenciación en el flujo de la realidad. Al diferenciar le da algún tipo de configuración a la realidad y con ello demarca las áreas de la realidad que servirán para construir el micromundo o mundo particular de que se trate. Para poder diferenciar los elementos es necesario hacer algún tipo de comparación sobre la base de un criterio de selección resultante del punto de vista adoptado.

b. Ordenar. Ordenar implica, ante todo, clasificar. Es horizontalmente establecer secuencias o contrastaciones, y verticalmente establecer jerarquías. De allí resultan las coordenadas de origen que permiten el establecimiento de una morfología específica.

c. Encontrar relaciones. La realidad tiene su propio logos. Dependiendo de los supuestos básicos de la reflexión lógica del científico, esa realidad puede aparecer como un caos, como lo irracional, como lo que no tiene orden, frente al científico que crea un cosmos, racionaliza lo irracional y le da un orden y coherencia. Pero es también posible ver la acción del científico como el proceso de progresivo acercamiento al $\log o s$ de la realidad. En ese caso, la manera en que la ciencia es autoexpresión de la realidad es mediante el descubrimiento de formas de relación. Entre estas formas de relación están la regularidad, la causalidad, etc.

d. Explicar. Explicar es llevar de nuevo a la intuición, a una intuición más amplia y profunda. En la fundamentación de cada ciencia hay una intuición base. Sobre esa intuición se construye cada ciencia. Explicar es dar sentido a las relaciones de la ordenación establecida a partir de la diferenciación de las vecindades de un micromundo particular. Para dar sentido a esas relaciones se debe volver a la intuición base. Ello implica un retorno al axioma fundamental de cada ciencia.

e. Comprobar. Las verdades obtenidas deben ser nuevamente atestiguadas por la realidad. Es decir, los 10,000 dharmas que han sido solidificados por el procedimiento científico en 'cosas' y 'hechos' deben ser testigos: su autoexpresión debe encontrarse en las verdades de la ciencia. Al partir de las cosas o de los hechos, en una obra de construcción social, los científicos han añadido a la realidad las coordenadas de su corporalidad histórica como órgano de la ciencia. El 
desmontaje de esa construcción viene a ser la verificación. Es decir, el análisis del juicio científico debe ser traído nuevamente a la autoexpresión de la realidad. Esta comprobación es parte de la organización del conocimiento en las ciencias.

En tanto que para Nishida el lenguaje conlleva comparación, taxonomía y designación, permite y acompaña la expresión de las operaciones básicas antes mencionadas. A partir de aquí podemos pasar a ver un poco más acerca del método general de las ciencias, todavía sin especificar si se trata de ciencias empíricas, ciencias naturales, ciencias sociales, etc. La manera en que según Nishida se fundamenta cada una de ellas queda para una investigación posterior.

\section{El carácter general del método de las ciencias}

Antes de hablar de los consabidos aspectos del método: teoría, hipótesis, experimento, comprobación/disprobación, explicación, etcétera, vamos a ver el carácter general del método de las ciencias que señala Nishida. De entre las muchas indicaciones que hace a lo largo de su carrera textual acerca del método de las ciencias, aquí he escogido sólo cinco que considero las más importantes.

a) La objetivación. El método de las ciencias es objetivante y se extiende desde lo que es totalmente ajeno al hombre hasta lo que le es más interno y recóndito: "pensar incluso lo subjetivo de manera objetiva es el método de las ciencias", 156

b) Mundo solidificado. La ciencia objetualiza todo, sobre todo en aquellos aspectos en que está directamente ligada al lenguaje: "allí donde negando al si-mismo activo solidificamos al mundo con lógica objetual, allí se constituye la ciencia. Ese es el método de la ciencia. Por eso, por medio de la actividad se piensa el reflejar", ${ }_{1}^{157}$

c) La lógica como fundamento. Las ciencias se desarrollaron en occi dente sobre la base de la lógica griega: "lo que Platón denominó dia-

${ }^{156}$ VIII: 129.
${ }^{157}$ VIII: 241. 
lektike como método de verdadero conocimiento es ya algo como lo que hoy en día pensamos que es la lógica. Esta fue perfeccionada por Aristóteles y, como lógica, vino a ser el fundamento del método científico hasta nuestros días"; 158

d) Aspecto topológico. Es necesario añadir una nueva dimensión al método de la ciencia para que esté más en consonancia con el avance en el conocimiento y para ello debe incorporar un aspecto topológico. El método de la ciencia debe incluir un aspecto topológico; ${ }^{159}$

e) Otro aspecto del carácter general del método de las ciencias es el del análisis intuitivo. Ese análisis debe centrarse en el presente absoluto y fundamentarse en la intuición activa como proceso infinito de autoexpresión del mundo y del absoluto: "podemos decir que el método de todas las ciencias es el análisis intuitivo" ${ }^{160}$ Pero ese análisis es constructivista e incorpora las características de un acercamiento geométrico que partiendo de axiomas o de postulados, definiciones, proposiciones y leyes generales llegue a la prueba de sus conclusiones. ${ }^{161}$

El carácter general de la ciencia radica en que el mundo autoexpresivo -en el que la forma se forma a sí misma-se refleje y se exprese a sí mismo intuitivo-activamente mediante un mirar que se despoja del que mira, es decir, mediante un ver sin vidente. De esta manera, según Nishida la filosofía debe ser la base de la ciencia y ésta tiene la intuición activa como su foco principal. ${ }^{162}$

El carácter de la ciencia en general

La ciencia es, ante todo, una forma de conocimiento dentro de una cosmovisión. Cuando esa cosmovisión implica un mundo, una realidad histórica que se autodetermina, se autoexpresa, se forma a sí misma y se percibe a sí misma, podemos entender por qué Nishida dice que a la

\footnotetext{
${ }^{158}$ VIII: 273.

${ }^{159} \mathrm{IX}: 257$.

${ }^{160} \mathrm{X}: 560$.

${ }^{161} \mathrm{XI}: 152$.

${ }^{162} \mathrm{XI}: 155-156$.
} 
base de la ciencia "está la autoexpresión del mundo". ${ }^{163}$ Por esto "para llegar a ser conocimiento académico, como lo es todo conocimiento científico, el si-mismo autoperceptivo debe venir a ser proceso autoperceptivo del mundo que es autoexpresivo" ${ }^{164}$ Esta manera de ver la realidad histórica, como dije anteriormente, es característica del pensamiento de Nishida, de su cosmovisión.

Por eso, al caracterizar la ciencia en general es necesario examinar en alguna medida los rasgos de esa cosmovisión. Nishida escribe que las ciencias se fundamentan "en el proceso infinito intuitivo-activo de la percepción de nosotros mismos que somos histórico corporales", ${ }^{165}$ es decir, "se fundamentan en el [hecho de] que nosotros vemos, históricocorporalmente, es decir, intuitivo-activamente, la forma que se da forma a sí misma". ${ }^{166}$ La autoexpresión del mundo se da allí donde mediante su praxis social-en la que volviéndose cosa piensa y actúa-cada uno de nosotros, como individuo único, "refleja al mundo y actúa como autoformación expresiva y única del mundo mismo" y, sin embargo, "el conocimiento científico [...] no pasa de ser la autoexpresión abstracta en el polo trascendental de un mundo que tiene caracter de autoidentidad de lo contradictorio". ${ }^{167}$ Dado que en su praxis social -que es también praxis religiosa o gyô-el si-mismo, tornándose cosa, piensa y actúa, "la ciencia y el arte deben ser gyô religioso" ${ }^{168}$

Para entender mejor esta última oración vamos a ver un poco de lo que Nishida dice acerca de la vida cotidiana y la manera en que implica la acción del hombre. Esta acción es creativa y el hombre la realiza como manifestación de la vivencia fundante.

No sólo la ciencia sino también la religión y el arte salen de la vida ordinaria del hombre y a ella retornan. Es decir, resultan de la experiencia cotidiana de la vida en este mundo histórico, en el que nacemos, trabajamos y hacemos las cosas, y morimos. ${ }^{169}$ La ciencia está directamente

\footnotetext{
${ }^{163} \mathrm{XI}: 112,83$

${ }^{164} \mathrm{XI}: 105$.

${ }^{165} \mathrm{XI}: 154$.

${ }^{166} \mathrm{X}: 471$.

${ }^{167} \mathrm{X}: 302$.

${ }^{168} \mathrm{IX}: 333$.

${ }^{169}$ XIV: 267.
} 
ligada a la vida práctica del si-mismo histórico corporal que tiene una morfología creativa: "lo que se llama ciencia debe ser algo nacido de la vida histórico-social, es decir, de la vida práctica de cada persona". ${ }^{170}$ Por eso, "hacer ciencia es actuar. En ese sentido, la actividad científica es dialéctica". ${ }^{171}$ Nos falta ver lo que Nishida quiere decir con la ciencia como gyô, es decir, como práctica espiritual.

Considero que para facilitar la comprensión de la ciencia como gyô será conveniente repetir algo de lo que sobre este concepto escribí en Filosofía social de Nishida Kitarô. El gyô es la actualización de la Nada Absoluta. Es la actividad del si-mismo activo que ha vivenciado históricocorporalmente la fuente y raíz misma de su propia existencia. En ese sentido es intuición creativa, es acción celestial del si-mismo asubstancial que ha dejado caer cuerpo y corazón. Es la acción creativa que brota de 'un corazón suave y flexible'. El gyô es la acción de un cuerpo que lleva en sí mismo la vivencia de su propio fundamento existencial y, por eso es creación, no es simplemente una acción externa al hombre: $\mathrm{y}$ "la creación es el centro de la existencia humana". Esta creación es autoformación y es autopercepción, y por ello debe haber allí una unidad indisoluble: "en lo que llamamos autopercepción debe haber unidad absoluta de la historia (es decir, de la base de lo creativo)". Esto se debe a que la creación, lo creador y la autopercepción "son puntos de autoproyección de Dios y por tanto tienen características de puntos básicos posicionales de la autopercepcion del mundo". La acción del individuo es así acción formativa del mundo histórico. Es una acción que originalmente proviene de la visión del Vacío, de la Nada Absoluta, y retorna a ella. Por eso, el gyô es, en el más elevado sentido de la palabra, "corporalizar la Nada Absoluta". ${ }^{172}$

Estos son algunos de los aspectos del carácter general de la ciencia en los que podemos apreciar algunos elementos orientales o japoneses.

\footnotetext{
${ }^{170} \mathrm{XI}: 267$.

${ }^{171}$ VIII: 244-245.

${ }^{172}$ Véase Agustín Jacinto Z., "The Bodily Manifestation of Religious Experience in Late Nishida Philosophy", en Thomas Kirchner (ed.), Zen Buddhism Today, Annual Report of the Kyoto Zen Symposium No. 15. Kyoto: The Kyoto Seminar for Religious Philosophy, noviembre 1998, 33-50. Id. La filosofía social de Nishida Kitarô: 1935-1945. pp. 210-211.
} 
En 1938, en sus conferencias sobre "Los problemas de la cultura japonesa", que después se convirtió en un libro con el mismo título, Nishida había señalado como uno de los grandes problemas de la cultura japonesa el siguiente: ¿cómo puede la cultura japonesa dejar de ser un pequeño mundo en un rincón del ancho mundo y convertirse en un elemento creativo de la cultura mundial?

Hablar del carácter localista, restringido y peculiar de la ciencia, que resulta del énfasis en lo que es oriental o es japonés, parecería negar uno de los supuestos más básicos de la ciencia, que es su universalidad. La visión universalista de la ciencia como conocimiento válido en todas partes de la realidad es un ideal. Ese ideal se ha aceptado sobre todo por el carácter mismo de la verdad obtenida por el método científico. Sin embargo, en tanto es producido en una cierta cultura, bajo un cierto modo de organización socioeconómica y política y, sobre todo, en tanto que se le ha utilizado para hacer una separación entre países avanzados y atrasados, ese ideal ha sido negado de muchas maneras. Este aspecto fue el que enfatizaron los partidarios del estatismo, o del militarismo o del ultranacionalismo militarista en tiempos de la Segunda Guerra Mundial en Japón.

Por otra parte, no se necesita ser estatista o militarista para concebir la ciencia, a la manera en que lo hizo Thomas Kuhn en La estructura de las revoluciones científicas allá por 1962, como un conocimiento aceptado por ciertos grupos específicos en el coto cerrado de la comunidad científica y que puede de ser validado siempre solamente siguiendo criterios establecidos por esos mismos grupos específicos. El cambio de paradigmas ocurre precisamente con el cambio en las membrecías de los grupos y en los criterios de validación, o cuando fuera de esos grupos se obtiene un conocimiento que no puede ser soslayado por la comunidad científica. Como Kuhn escribe: "el conocimiento científico [...] es, intrínsecamente, la propiedad común de un grupo, o no es nada en absoluto"..$^{173}$

En el caso que nos ocupa, Nishida fue partidario del valor universal de las verdades obtenidas mediante el método científico pero sin dejar

${ }^{173}$ Thomas Kuhn, La estructura de las revoluciones cientificas, México, Fondo de Cultura Económica, 1983, 319. Postdata de 1969. 
de criticar los criterios de validación de esas verdades. Allí es donde entra la visión de la realidad, la visión del proceso del conocimiento y la lógica del topos que juntos constituyen una manera diferente de producir conocimiento científico que puede hacer una contribución a la tradición europea de la ciencia.

Por esto, Nishida no trata simplemente de proponer un concepto alternativo de la ciencia, sino quiere aportar, mediante la crítica y la propuesta de procedimientos provenientes de una cultura diferente a la europea, elementos que puedan profundizar y ampliar el concepto de ciencia europea de los siglos XIX y XX. Esta es parte de su respuesta al problema mencionado al comienzo de esta sección.

La ciencia para su constitución depende también de la tradición, ya que "la ciencia en realidad no se constituye si no hay tradición". ${ }^{174}$ Es por la vía de la integración creativa en el verdadero encuentro entre tradiciones de diferentes etnias y culturas, como Nishida busca resolver el problema de la formación de un mundo global.

El espíritu japonés --es decir la etnicidad-- y el espíritu científico --es decir, la ciencia-- están estrechamente relacionados en un punto importante: en ir a la realidad de las cosas. Ya antes se dijo que Nishida escribe que el espíritu japonés radica en 'solamente ir por el camino que va a las cosas'. Pero "ir a la realidad de las cosas no es simplemente seguir por costumbre la tradición, ni actuar de acuerdo con nuestros sentimientos subjetivos. Ir por entero a la realidad de las cosas debe también incluir el espíritu científico. Y este debe ser un seguir la realidad de las cosas negándose a sí mismo". ${ }^{175}$ Igualmente, afirma que "si el verdadero espíritu científico reside en ir a la realidad de las cosas, debe ser una aprehensión entera del mundo. Debe ser tan positivo como sea posible". ${ }^{176}$

Un último punto que habrá que tratar en otra ocasión es la manera en que Nishida concibe la consciencia: hay consciencia social y consciencia individual. En la consciencia individual hay conocimiento, sentimiento y voluntad individual. De la misma manera, en la consciencia social hay conocimiento, que es la ciencia; hay sentimiento, que es el

\footnotetext{
${ }^{174}$ XIV: 383.

${ }^{175}$ XII: $279-280$.

${ }^{176}$ XII: 345.
} 
arte; y hay voluntad, que es la norma. El paso de una etapa a la otra se da a través de la intersubjetividad y de la interacción institucional, es decir, a través de los agentes de la realidad histórica.

\section{CONCLUSIÓN}

La presentación anterior en gran medida es el aspecto sociológico del concepto de ciencia en cuanto está referido a la etnia. Con esto, apenas tocamos uno -notable quizá, pero sólo uno- de los aspectos de la reflexión nishidiana sobre la ciencia. Hasta aquí hemos visto principalmente lo que Kuhn denomina el "paradigma metafísico"177 y (para darle algún nombre) el paradigma epistemológico en lo que podríamos llamar la matriz de la ciencia en Nishida Kitarô. Es el aspecto en que Nishida presenta "una constelación de conjuntos mentales"178 de origen oriental que conllevan otra manera de ver lo que es la realidad y la naturaleza. ${ }^{179}$ Faltan los aspectos del diálogo crítico con los pensadores occidentales, la discusión sobre la fundamentación de la ciencia, lo que es el espíritu científico, la clasificación de las ciencias, los conceptos básicos de la ciencia, la relación entre ciencia y técnica, y los lugares donde puede haber integración o, quizá, en algún sentido, un cambio de paradigma en el concepto general de ciencia.

Para terminar, quisiera solamente citar un párrafo en que Nishida hace su crítica del entusiasmo exagerado por la "ciencia japonesa".

La palabra más de moda, [más] superficial y aventurada en nuestros días es "ciencia japonesa". Con sólo anteponer el adjetivo 'japonés' no le sucede nada a esa ciencia. No importaría, si los japoneses la hubieran hecho, pero pienso que todavía no han hecho eso. Quizá sobrepasemos a los extranjeros

${ }^{177}$ Kuhn. Op.cit.p. 282. Como el lector podrá haber advertido, todavía aquí quedan sin tocar temas importantísimos tales como la experiencia, la evidencia, el papel de la hipótesis, la inducción, la deducción y otros aspectos metodológicos. Tampoco se ha tocado un tema importante en Nishida, que es un explicación del surgimiento de las ciencias "naturales" y las ciencias "sociales".

${ }^{178}$ Op.cit.p. 311.

${ }^{179}$ Cf. op. cit. p. 314. 
en cuanto a la aplicación. Pero todavía no existen los principios fundamentales de las ciencias japonesas. Alemania, Inglaterra, Francia, etc., los tienen. Por ejemplo, las matemáticas se supone que son lo mismo independientemente de quién las haga y, como es de suponer, según el país hay procedimientos diferentes. Pero aunque se hable de pronto de una "ciencia japone$\mathrm{sa}^{\prime \prime}$, no es algo que se pueda hacer fácilmente. ${ }^{180}$

Después de esto Nishida pasa revista a los esfuerzos por hacer una "ciencia japonesa" en las áreas de las ciencias naturales, en las matemáticas, en las ciencias culturales, el derecho y la economía. Encuentra que hay todavía muchas áreas en las que no se ha avanzado suficiente aunque sí se proclama el espíritu étnico.

También advierte contra los excesos de la exaltación del espíritu japonés y de su peculiaridad en un mundo que se ha unificado globalmente: "hoy día en que el mundo se ha hecho real, no se puede enfrentar al mundo con solo esta peculiaridad. Si nos enorgullecemos solamente de la peculiaridad, nos vemos llevados a rechazar todo lo que sea diferente a ella" ${ }^{181}$ Como resultado de su propia observación, Nishida está convencido de que ninguna de las disciplinas académicas en Japón llena ni el mínimo de las características señaladas en el cuerpo de este escrito, y por eso afirma en 1938 que "aunque se hable de pronto de una 'ciencia japonesa', no es algo que se pueda hacer fácilmente”, como se lee en la cita anterior.

Por vía de comparación, quiero mencionar que en septiembre de 1941, el físico Yukawa Hideki (en la posguerra recibió el Premio Nobel) que en ese momento se inclinaba por la idea gobiernista de Japón como líder de la construcción de la Gran Esfera de Coprosperidad de Asia, escribe en su artículo "La tradición de la ciencia":

En ciencia, Japón es un país atrasado. No es fácil alcanzar y sobrepasar a los países avanzados de Europa y [Norte]América. Este tipo de opinión recientemente ha sido enfatizado por muchas gentes.[...] La ciencia y la técnica de nuestro país en unas partes están más avanzadas que en el extranjero, y no

180XIV: 400

${ }^{181} \mathrm{XIV}: 402$. 
hay duda de que en otras están atrasadas. Este pequeño atraso viene a ser un gran problema. Especialmente ahora en que la presión de la situación internacional ha venido a hacer que sea urgente la demanda de un súbito avance de la ciencia y la técnica en nuestro país y de liberarse completamente de la dependencia del extranjero. ${ }^{182}$

Se refiere Yukawa al problema del "pequeño atraso" diciendo que es difícil de remediar porque "en nuestro país casi no hay tradición de la ciencia y, aunque lo haya, es muy corto para llamarle tradición". ${ }^{183}$

Nishida considera que mientras no haya una integración creativa de todas las culturas en una cultura mundial, la presentación del punto de vista de cada una de ellas por separado tiende a ser unilateral y en ese sentido debe ser negado y complementado. El propio esfuerzo de Nishida consistió en tratar de ver tanto el punto de vista oriental como el punto de vista occidental y de producir a partir de ellos un pensamiento creativo.

Quisiera terminar con una cita en que Nishida manifiesta la dificultad que hay para convertir la cultura japonesa en un elemento de la cultura mundial y para hacer una contribución a ésta: "aquello que puede erigirse como cultura mundial debe salir de las entrañas de los japoneses. Es una empresa muy grande. Se habla como si ya mañana se pudiera de inmediato lograr, pero no es así" ${ }^{184}$ De hecho, en 1943, Nishida menciona entre las causas de la derrota del Japón en la Segunda Guerra Mundial la carencia de un pensamiento científico racional y la falta de organización sistemática entre los japoneses combatientes. ${ }^{185}$

No quisiera terminar en tono negativo, pero si tuviéramos que escoger un ejemplo de un científico japonés proponente de la "ciencia japonesa" podríamos señalar a Hashida Kunihiko. Después de graduarse de la escuela de Medicina en la universidad de Tokio (1908), estudió fisiolo-

${ }^{182}$ Yukawa Hideki, Kyokubi no sekai (El mundo de lo microscópico), Iwanami Shoten, Tokio, 1942, 128.

${ }^{183}$ Ibid. p. 129.

${ }^{184}$ XIV: 402-403.

${ }^{185}$ Véase mi artículo "La guerra vista desde Kamakura -Reflexiones de Nishida Kitaro sobre la Segunda Guerra Mundial". Universidad Iberoamericana, Humanidades, vol. V, 1982, 213- 241. 
gía en el extranjero (1914-1918), obtuvo el doctorado de su alma mater (1921), desempeñó cargos académicos, tuvo puestos políticos (entre ellos el de ministro de educación en 1940-1943), propuso coherentemente la idea de una "ciencia japonesa", y al ser llamado a comparecer ante los tribunales al final de la Segunda Guerra Mundial prefirió darse muerte. Por haber tenido la influencia de varios miembros de la Escuela de Kioto, en especial de Nishida Kitarô y de Tanabe Hajime, se expresó con un lenguaje semejante al de éstos. ${ }^{186}$ Sin embargo, no llega a concretar esa "ciencia japonesa" en su propia disciplina, ni identifica alguna otra que pueda ser clasificada como tal. Por lo que podemos colegir que las apreciaciones críticas antes mencionadas de Nishida Kitarô y de Yukawa Hideki fueron correctas: esa "ciencia japonesa" estaba por hacerse.

\section{BibLIOGRAFÍA}

Dôgen ZenII, Shôbôgenzô. The Eye adn Treasury of the True Law, Traducción de Kôsen Nishiyama, Tokio, Nakayama Shobô, 1988.

FicHTE, Immanuel H., Das Erkenntnis als Selbsterkennen, Heidelberg, 1833 (primer volumen de la obra Gründzuge zum Systeme der Philosophie). Consultado como E-book en Gallica N0095392, www.bnf.fr.

ITô KichinosuKe, Iwanami tetsugaku shô-jiten (Pequeño Diccionario de filosofía de [la Editorial] Iwanami), Tokiom, Iwanami shoten, 1949.

JaCINTO Z., Agustín, "La guerra vista desde Kamakura -Reflexiones de Nishida Kitaro sobre la Segunda Guerra Mundial", Universidad Iberoamericana, Humanidades, vol. V, 1982, 213- 241.

"La misión de la filosofía en Visible et Invisible de Merleau-Ponty", en Estudios: filosofía/ historia/ letras, México, ITAM, núm. 17, verano 1989, 25-49.

-, Filosofía de la transformación del mundo, Zamora, El Colegio de Michoacán, 1989.

La filosofía social de Nishida Kitarô: 1935-1945, Zamora, El Colegio de Michoacán, 1995.

${ }^{186}$ Yoshinaka Masakazu, Kagakusha no hassô (La inspiración de los científicos), Tokio, Tamagawa daigaku shuppan-kai, 1984, 179-223. 
,"Tradition and the Problem of Knowledge in Nishida Philosophy" en Dokkyô International Review, Sôka-shi, Saitama-ken, Japón, núm. 14, 2001, 91-135.

, "The Bodily Manifestation of Religious Experience in Late Nishida Philosophy", en Thomas Kirchner (ed.), Zen Buddhism Today, Annual Report of the Kyoto Zen Symposium, núm. 15, Kyoto, The Kyoto Seminar for Religious Philosophy, noviembre 1998, 33-50.

-, Tradición y mundo histórico en la filosofía de Nishida Kitarô, Zamora, El Colegio de Michoacán, 2004.

JAMES, William, Pragmatismo, Madrid, SARPE, 1984.

KunN, Thomas, La estructura de las revoluciones científicas, México, Fondo de Cultura Económica, Postdata de 1969, 1983, 319.

NieTzsCHE, Friedrich, Obras selectas, Madrid, Edimat libros, s.f.

Nishida Kitarô Zensh û (Obras completas de Nishida Kitarô), Tokio, Iwanami shoten, 19 vols., 1966-1968.

Nishimura SeY, "The Way of the Gods. Motoori Norinaga's Naobi no Mitama" en Monumenta Nipponica, Tokio, Sophia University, vol. 46, núm. 1, primavera de 1991, 21-41.

NonAKA, Ikujiro y Hirotaka TAKeUCHI, The Knowledge Creating Company, Nueva York, Oxford University Press, 1995.

Toffler, Alvin y Heidi Toffler, La revolución de la riqueza, México, Debate, 2006.

- La creación de una nueva civilización: la política de la tercera ola, Barcelona, Plaza y Janés, 1996.

Thurow, Lester C., Construir riqueza, Buenos Aires, Javier Vergara Ed., 2000.

YoshinaKa MASAKAZu, Kagakusha no hassô (La inspiración de los científiCos), Tokio, Tamagawa daigaku shuppan-kai, 1984.

YuKaWa HiDEKI, Kyokubi no sekai (El mundo de lo infinitesimal), Tokio, Iwanami Shoten, 1942.

FECHA DE RECEPCIÓN DEL ARTículo: 25 de agosto de 2009

FECHA DE ACEPTACIÓN Y RECEPCIÓN DE LA VERSIÓN FINAL: 15 de abril de 2010 